\title{
Effects of Unilateral Climate Policy on Terms of Trade, Capital Accumulation, and Welfare in a World Economy
}

\author{
KARL FARMER \\ BIRGIT FRIEDL \\ ANDREAS RAINER
}

CESIFO WORKING PAPER NO. 2375

CATEGORY 8: RESOURCES AND ENVIRONMENT

August 2008

Presented AT CESifo Venice SuMmer Institute 2008, Workshop ON

'EUROPE AND GLOBAL ENVIRONMENTAL ISSUES'

An electronic version of the paper may be downloaded

- from the SSRN website: Www.SSRN.com

- from the RePEc website: $\quad$ www.RePEc.org

- from the CESifo website: www.CESifo-group.org/wp 


\title{
Effects of Unilateral Climate Policy on Terms of Trade, Capital Accumulation, and Welfare in a World Economy
}

\begin{abstract}
We present a two-good, two-country overlapping generations model where emissions arise from production and each country has a domestic emission permit system. When one country unilaterally reduces her cap on emissions, her output available for domestic and foreign consumption diminishes more than in the other country. With unchanged consumption expenditure shares for both goods the terms of trade improve, while capital stocks decline in the reducing and less strongly in the non-reducing country. The net welfare effect of improving terms of trade and falling capital stocks is negative in both countries. However, if the country which unilaterally reduces her emission permits is a net creditor to the world economy, her own welfare loss remains below that of the non-reducing country.
\end{abstract}

JEL Code: F11, Q56, D91.

Keywords: capital accumulation, emission permits, terms of trade, overlapping generations, welfare.

\author{
Karl Farmer \\ Department of Economics \\ University of Graz \\ Universitätsstrasse 15 \\ Austria - $8010 \mathrm{Graz}$ \\ karl.farmer@uni-graz.at
}

\author{
Birgit Friedl \\ University of Graz \\ $8010 \mathrm{Graz}$ \\ Austria \\ birgit.friedl@uni-graz.at
}

\section{Andreas Rainer \\ University of Graz \\ Austria - 8010 Graz \\ andreas.rainer@uni-graz.at}

We would like to thank Tetsuo Ono and Ronald Wendner for their comments on an earlier version of this paper, and the Jubiläumsfonds der Oesterreichischen Nationalbank (project No. 12290) for financial support. The views expressed in the paper do not imply an endorsement by the funding agency. Moreover, we would like to thank for discussions and inputs by conference participants of SURED 2008 in Ascona (Switzerland), EAERE 2008 in Gothenborg (Sweden), ECOMOD 2008 in Berlin (Germany), and particularly Karsten Neuhoff, Ray Riezman, and John Whalley for discussion during the CESifo Venice Summer Institute workshop on "Europe and Global Environmental Issues" on San Servolo island (Italy). 


\section{Introduction}

When both the Kyoto Protocol and the European Emissions Trading Scheme came into force in 2005, there was considerable dispute concerning the different potential and real impacts on trade relations between the European Union and non-participating competitor countries (e.g., Grubb and Neuhoff, 2006; Van Asselt and Biermann, 2007). A cap on emissions in the European Union induces domestic firms to reduce output and affects the domestic trade balance which might lead to an improvement of the domestic terms of trade. ${ }^{1}$ Moreover, the cap has a negative impact on domestic income which in turn reduces domestic savings and hence domestic and foreign capital accumulation. This also leads to adverse effects on domestic and foreign consumers' welfare (Fischer and Fox, 2007; Kuik and Gerlagh, 2003). Thus, the burden of unilateral policy is shifted - at least partly-from domestic consumers to consumers abroad (Babiker, 2005; Proost and Van Regemorter, 2004). We will show in this paper for a world economy consisting of two large economic areas, that the magnitude of this burden-shifting effect depends on the external balance of the country implementing a unilateral climate policy.

The consequences for terms of trade, capital accumulation, and welfare have been discussed intensively for unilateral fiscal policy. Regarding the terms of trade effect, Frenkel and Razin (1986) found in a two-period intertemporal equilibrium model that the effect of unilateral fiscal expansion on domestic terms of trade depends on the external balance (i.e., the net foreign asset position) of that country. In a model with endogenous capital accumulation, Lipton and Sachs (1983) show that the impact on domestic and foreign capital accumulation is unambiguously negative. The economic reason for this decline in capital accumulation is that government debt implies an increase in the tax burden which reduces both savings of younger households and the supply of loanable funds for private capital accumulation (Zee, 1987). We will show that a qualitatively similar result can be found for a more stringent unilateral environmental policy, in spite of a rising price of emission permits.

\footnotetext{
${ }^{1}$ This terms of trade improvement can be interpreted as a sort of reversed "immiserizing growth" effect à la Bhagwati (1958).
} 
Because of the international transmission of a unilateral fiscal expansion, welfare impacts emerge domestically and abroad. Domestic intertemporal welfare is affected through different channels, acting in opposite directions. In a one-commodity model, the welfare effect of a unilateral fiscal expansion can be decomposed into a positive interest rate effect and a negative lifetime net income (or wealth) effect (Persson, 1985). In a two-good, twocountry framework a third positive welfare impact is caused by a terms of trade effect, leading to an ambiguous net welfare effect for Home and for Foreign (Ono and Shibata, 2005). ${ }^{2}$ In the dynamic context of our two-country model, we analyze the welfare effect of unilateral climate policy by considering the opposing forces of all three effects and by comparing the welfare effects at home and abroad. In this way, we are able to analyze the burden-shifting hypothesis which was discussed above for a static world: in an integrated world economy consisting of (two) large economic areas, a positive terms of trade effect at home implies a negative one abroad.

We model a world economy consisting of two large industrialized countries, interconnected through free trade in produced commodities and in bonds emitted by national governments. The model is based on Diamond's (1965) overlapping generations economy with productive capital and constitutes an extension of the closed economy model of Ono (2002) towards a two-country setting. Pollution arises from production and is controlled by a permit market in each country. There are two tradeable goods with perfect specialization in each country. Following the set-up of the dynamic Heckscher-Ohlin models (see Chen, 1992; and more recently Ono and Shibata, 2005), we assume identical technologies and preferences across countries. Regarding international trade, commodities and government bonds are internationally mobile, labor and real capital are not. As a prerequisite for the emergence of international trade, countries differ in their levels of public debt per capita such that one country is a net creditor and the other one is a net debtor to the world economy.

\footnotetext{
${ }^{2}$ In contrast, in a static closed economy model the only effect of a more stringent unilateral environmental policy is a wealth effect (Hoel, 1991), while in a static open economy the only effect is the terms of trade effect (Copeland and Taylor, 2005).
} 
To analyze the transitional dynamics and steady state effects of unilateral climate policy, the number of permits issued in Home is exogenously reduced. We disentangle the consequences for the terms of trade, capital accumulation, and welfare, and show that the magnitude of the domestic welfare effect and of the burden-shifting effect depends on the country's net foreign asset position. Our key finding is that if the country which unilaterally reduces its emissions permits is a net creditor to the world economy, like the European Union, the domestic welfare effect is smaller and the foreign welfare effect is larger than if she were a net debtor like the United States.

This paper has five sections. The next section provides a description of the two-good, twocountry model with nationally tradable emission permits, and investigates the existence and stability of steady state equilibria. In Section 3, the steady state and transitional effects caused by a unilateral permit reduction, both on the terms of trade, and on domestic and foreign capital accumulation are analyzed. We investigate the net welfare effect of such a unilateral permit reduction in Section 4. Section 5 summarizes our results and concludes.

\section{The Basic Model}

Consider an infinite-horizon world economy of two countries, Home $H$ and Foreign $F$, which have the same population normalized to unity. Each country is composed of perfectly competitive firms and finitely lived consumers. Both countries have identical preferences and production technologies. They differ, however, in their levels of public debt per capita, leading to diverging net foreign asset positions across countries. This assumption is essential for the emergence of international trade in a large open economy framework.

There are two tradeable goods, $x$ and $y^{*}$, and each country specializes in the production of a unique good, which can be used for the purpose of consumption in both countries as well as for investment. ${ }^{3}$ Both goods are produced by employing labor and capital, and both

\footnotetext{
${ }^{3}$ This assumption is a deviation of our model from the assumptions of the Heckscher-Ohlin model.
} 
cause a flow of pollution. Households save in terms of internationally immobile capital and internationally mobile government bonds, where the supply of government bonds in each country is constant over time (as in Diamond, 1965). Without loss of generality, the rate of depreciation can be set at one, enabling investment of the current period to form next period's capital stock.

Regarding pollution and climate policy, we follow the established literature and focus on producer emissions (Ono, 2002; Jouvet et al., 2005a,b). Due to the assumption of identical technologies across countries (and sectors), the production of each good causes pollution. In line with the empirical evidence of the European Emission Trading System (ETS), we model country-specific emission trading systems where each country's government exogenously sets a cap on carbon emissions caused by domestic production. ${ }^{4}$

\section{$2.1 \quad$ Production}

Let the domestically produced good be $x$ and the foreign-produced good be $y^{\star}$, both in per capita terms (in the following, all foreign-country variables are denoted by a superscript asterisk). Countries Home and Foreign are assumed to have the same Cobb-Douglas constant-returns-to-scale production technology in per capita terms:

$$
\begin{aligned}
& x_{t}=M\left(k_{t}\right)^{\alpha_{K}}\left(p_{t}\right)^{\alpha_{P}}, \\
& y_{t}^{\star}=M\left(k_{t}^{\star}\right)^{\alpha_{K}}\left(p_{t}^{\star}\right)^{\alpha_{P}},
\end{aligned}
$$

where $M$ denotes a productivity scalar, $k_{t}\left(k_{t}^{\star}\right)$ and $p_{t}\left(p_{t}^{\star}\right)$ are respectively the capitallabor ratio and the pollution-labor ratio in $H(F) .^{5}$

Our model can be regarded as an OLG analoguous to Obstfeld's (1989) and Gosh's (1992) two-good, two-country ILA models.

${ }^{4}$ Alternatively, one could model a global emissions trading system, which would lead to equal permit prices across countries. Another possibility would be to assume that goods consumed domestically (rather than those produced) fall under the permit trading scheme.

${ }^{5}$ Ono $(2002,77)$ shows how, by rescaling parameters, a production function exhibiting constant returns to scale with respect to labor and capital, and with emission intensity as a scaling factor, can be 
In each country and each period, the long-lived government sets an emissions cap and assigns corresponding emission permits to the production sector, where the total number of emission permits is denoted by $S$ in Home and by $S^{\star}$ in Foreign. Following the specification of the permit market in Ono (2002), emission permits are distributed free of charge to the firms. If a firm's emissions exceed its allowance, then it buys emission permits in the market, while for the opposite case it sells excess permits.

In each period, firms in Home (and analogously for Foreign) choose $k$ and $p$ to maximize profit $\pi_{t}$ :

$$
\pi_{t}=x_{t}-q_{t} k_{t}-w_{t}+e_{t}\left(S-p_{t}\right)
$$

where $q_{t}\left(q_{t}^{\star}\right)$ is the rental price of capital, $w_{t}\left(w_{t}^{\star}\right)$ is the wage rate, and $e_{t}\left(e_{t}^{\star}\right)$ is the permit price in Home (Foreign). As described above, emission permits are traded in a perfectly competitive market. Since, moreover, firms rent capital and employ labor in perfect factor markets, the optimality conditions for maximizing profits in each period are given by:

$$
\begin{aligned}
q_{t} & =\alpha_{K} M\left(k_{t}\right)^{\alpha_{K}-1}\left(p_{t}\right)^{\alpha_{P}}=\alpha_{K} \frac{x_{t}}{k_{t}}, \\
w_{t} & =\left(1-\alpha_{K}-\alpha_{P}\right) M\left(k_{t}\right)^{\alpha_{K}}\left(p_{t}\right)^{\alpha_{P}}=\left(1-\alpha_{K}-\alpha_{P}\right) x_{t}, \\
e_{t} & =\alpha_{P} M\left(k_{t}\right)^{\alpha_{K}}\left(p_{t}\right)^{\alpha_{P}-1}=\alpha_{P} \frac{x_{t}}{p_{t}}, \\
q_{t}^{\star} & =\alpha_{K} M\left(k_{t}^{\star}\right)^{\alpha_{K}-1}\left(p_{t}^{\star}\right)^{\alpha_{P}}=\alpha_{K} \frac{y_{t}^{\star}}{k_{t}^{\star}}, \\
w_{t}^{\star} & =\left(1-\alpha_{K}-\alpha_{P}\right) M\left(k_{t}^{\star}\right)^{\alpha_{K}}\left(p_{t}^{\star}\right)^{\alpha_{P}}=\left(1-\alpha_{K}-\alpha_{P}\right) y_{t}^{\star}, \\
e_{t}^{\star} & =\alpha_{P} M\left(k_{t}^{\star}\right)^{\alpha_{K}}\left(p_{t}^{\star}\right)^{\alpha_{P}-1}=\alpha_{P} \frac{y_{t}^{\star}}{p_{t}^{\star}} .
\end{aligned}
$$

Profit maximization implies that the firm's revenues net of the payments to production factors give a profit equal to the initial endowment of permits, $e_{t} S$. This profit is collected by the government and reimbursed to the young households. ${ }^{6}$

transformed into a three-factor constant returns to scale production function with labor, capital and pollution as inputs.

${ }^{6}$ In essence, this particular modeling of the permit system guarantees that the subsidy is nondistortionary and that permits are not "grandfathered". 


\subsection{Consumption}

Each country is inhabited by identical consumers and each generation lives for two periods, one working and one retirement period. In Home, the representative consumer's intertemporal utility depends on consumption during the working period, composed of the consumption goods of both countries, $x_{t}^{1}$ and $y_{t}^{1}$, and consumption during the retirement period, $x_{t+1}^{2}$ and $y_{t+1}^{2}$, and similarly for Foreign. For simplicity, the representative households of countries $H$ and $F$ are assumed to have identical preferences across goods $(0<\zeta<1)$ and over time $(0<\beta<1)$ and are represented by a log-linear intertemporal utility function:

$$
\begin{gathered}
U_{t}=\zeta \ln x_{t}^{1}+(1-\zeta) \ln y_{t}^{1}+\beta\left[\zeta \ln x_{t+1}^{2}+(1-\zeta) \ln y_{t+1}^{2}\right], \\
U_{t}^{\star}=\zeta \ln x_{t}^{\star, 1}+(1-\zeta) \ln y_{t}^{\star, 1}+\beta\left[\zeta \ln x_{t+1}^{\star, 2}+(1-\zeta) \ln y_{t+1}^{\star, 2}\right] .
\end{gathered}
$$

In maximizing intertemporal utility the young household in Home is constrained by a budget constraint in each period of life. When young, wage income $w_{t}$, net of a lumpsum tax $\tau_{t}$ imposed by the national government, is spent on consumption of the Home and the Foreign good, with $h_{t}$ denoting the terms of trade of Home (units of Foreign good per unit of Home good). Furthermore, for transferring income to their retirement period, young households save in terms of domestic capital $k_{t+1}$ and in terms of bonds of Home $b_{t+1}^{H}$ and of Foreign $b_{t+1}^{\star, H}$. From saving, the old household gains interest income, where $i_{t+1}$ and $i_{t+1}^{\star}$ denote the interest rates in Home and Foreign. When old, the household spends interest income and capital on consumption, again for the Home and Foreign good $\left(x_{t+1}^{2}\right.$ and $y_{t+1}^{2}$, respectively). Thus, the first period budget constraint is given by:

$$
x_{t}^{1}+\frac{1}{h_{t}} y_{t}^{1}+s_{t}=w_{t}-\tau_{t},
$$

where savings are defined as

$$
s_{t} \equiv k_{t+1}+b_{t+1}^{H}+\left(1 / h_{t}\right) b_{t+1}^{\star, H} .
$$

After taking account of the no-arbitrage condition of the asset market in Home $\left(1+i_{t}=\right.$ $\left.q_{t}, \forall t\right)$, the second period budget constraint is given by:

$$
x_{t+1}^{2}+\frac{1}{h_{t+1}} y_{t+1}^{2}=\left(1+i_{t+1}\right)\left[k_{t+1}+b_{t+1}^{H}\right]+\left(1+i_{t+1}^{\star}\right) \frac{1}{h_{t+1}} b_{t+1}^{\star, H} .
$$


The corresponding budget constraints for the Foreign consumer are:

$$
\begin{gathered}
h_{t} x_{t}^{\star, 1}+y_{t}^{\star, 1}+s_{t}^{\star}=w_{t}^{\star}-\tau_{t}^{\star}, \\
s_{t}^{\star} \equiv k_{t+1}^{\star}+b_{t+1}^{\star, F}+h_{t} b_{t+1}^{F} . \\
h_{t+1} x_{t+1}^{\star, 2}+y_{t+1}^{\star, 2}=\left(1+i_{t+1}^{\star}\right)\left(k_{t+1}^{\star}+b_{t+1}^{\star, F}\right)+h_{t+1}\left(1+i_{t+1}\right) b_{t+1}^{F} .
\end{gathered}
$$

\subsection{Intertemporal Equilibrium Dynamics}

Using market equilibrium conditions for each period, we examine the intertemporal equilibrium dynamics of this world economy. Since government bonds are perfectly mobile across Home and Foreign, the real interest parity condition holds across both countries

$$
\left(1+i_{t+1}^{\star}\right) \frac{h_{t}}{h_{t+1}}=\left(1+i_{t+1}\right)
$$

Considering the two national no-arbitrage conditions of asset markets $\left(1+i_{t}=q_{t}, 1+i_{t}^{\star}=\right.$ $\left.q_{t}^{\star}, \forall t\right)$ and the firms' first order conditions (1) and $\left(1^{\star}\right)$ in $(8)$, the equation of motion of the terms of trade follows

$$
h_{t+1}=h_{t} \frac{\left(k_{t+1}^{\star}\right)^{\alpha_{K}-1}\left(S^{\star}\right)^{\alpha_{P}}}{\left(k_{t+1}\right)^{\alpha_{K}-1}(S)^{\alpha_{P}}} .
$$

Market clearing for Home and Foreign bonds demands

$$
b=b_{t}^{H}+b_{t}^{F}, \quad b^{\star}=b_{t}^{\star, H}+b_{t}^{\star, F}, \quad \forall t,
$$

where total bonds issued are, due to the assumption of a "constant stock" budget policy, time-stationary and denoted by $b$ in Home and by $b^{\star}$ in Foreign.

Utility maximizing domestic savings are given by $s_{t}=\sigma\left(w_{t}-\tau_{t}\right), \sigma \equiv \beta /(1+\beta)$, and foreign optimal savings by $s_{t}^{\star}=\sigma\left(w_{t}^{\star}-\tau_{t}^{\star}\right)$. Clearing of the world asset market requires the supply of savings to be equal to the demand for savings (from $(6),\left(6^{\star}\right)$, and (10)):

$$
s_{t}+\frac{1}{h_{t}} s_{t}^{\star}=k_{t+1}+b+\frac{1}{h_{t}}\left[k_{t+1}^{\star}+b^{\star}\right], \quad \forall t .
$$


This equation thus relates the terms of trade movements to capital accumulation and to the levels of domestic and foreign debt. Defining the net foreign asset positions of Home and Foreign as

$$
\phi_{t+1} \equiv k_{t+1}+b-s_{t}, \quad \phi_{t+1}^{\star} \equiv k_{t+1}^{\star}+b^{\star}-s_{t}^{\star},
$$

(11) can be rewritten as:

$$
h_{t}=-\frac{k_{t+1}^{\star}+b^{\star}-s_{t}^{\star}}{k_{t+1}+b-s_{t}} \equiv-\frac{\phi_{t+1}^{\star}}{\phi_{t+1}}, \quad \forall t .
$$

Since $h_{t}>0$, either $\phi_{t+1}<0$ and consequently $\phi_{t+1}^{\star}>0$, i.e. Home is a net creditor to the world economy and Foreign a net debtor, or vice versa if $\phi_{t+1}>0$ and $\phi_{t+1}^{\star}<0$. According to (13), terms of trade movements are determined by changes in the relative capital account positions of Home and Foreign. For instance, if Home is initially a net creditor, increasing terms of trade are the consequence of Home becoming a stronger net creditor to the world economy (and consequently Foreign a stronger net debtor).

To derive the combined product market clearing condition, we start by stating the budget constraints of Home's and Foreign's government:

$$
\tau_{t}+e_{t} S=i_{t} b, \quad \tau_{t}^{\star}+e_{t}^{\star} S^{\star}=i_{t}^{\star} b^{\star}
$$

Reformulating the first period budget constraint for $s_{t}\left(s_{t}^{\star}\right)$, substituting for taxes from (14), for the optimal consumption quantities and for the firm's first order conditions (1)(3), acknowledging the no-arbitrage condition for the domestic asset market, and clearing of permit markets $\left(p_{t}=S, p_{t}^{\star}=S^{\star}, \forall t\right)$, yields an expression for $s_{t}\left(s_{t}^{\star}\right)$ which depends only on $k_{t}\left(k_{t}^{\star}\right)$ and exogenously given parameters. By inserting these expressions into the international asset market clearing condition (11), we obtain the second equation of motion:

$$
h_{t} k_{t+1}+k_{t+1}^{\star}=h_{t}\left[\sigma_{0}\left(k_{t}\right)^{\alpha_{K}}-b\left(\sigma i_{t}+1\right)\right]+\sigma_{0}^{\star}\left(k_{t}^{\star}\right)^{\alpha_{K}}-b^{\star}\left(\sigma i_{t}^{\star}+1\right),
$$

where $\sigma_{0} \equiv\left(1-\alpha_{K}\right) \sigma M S^{\alpha_{P}}$ and $\sigma_{0}^{\star} \equiv\left(1-\alpha_{K}\right) \sigma M\left(S^{\star}\right)^{\alpha_{P}}$.

Clearing of Home's product market requires that domestic supply balances with domestic demand and exports $\left(x_{t}^{\star, 1}+x_{t}^{\star, 2}\right)$ :

$$
x_{t}=x_{t}^{1}+x_{t}^{2}+k_{t+1}+x_{t}^{\star, 1}+x_{t}^{\star, 2}, \quad \forall t,
$$


and for Foreign, that foreign supply balances with foreign demand and domestic imports $\left(y_{t}^{1}+y_{t}^{2}\right)$ :

$$
y_{t}^{\star}=y_{t}^{\star, 1}+y_{t}^{\star, 2}+k_{t+1}^{\star}+y_{t}^{1}+y_{t}^{2}, \quad \forall t
$$

where

$$
\begin{aligned}
x_{t}^{1} & =\frac{\zeta}{1+\beta}\left(w_{t}-\tau_{t}\right), & x_{t}^{\star, 1} & =\frac{\zeta}{1+\beta} \frac{\left(w_{t}^{\star}-\tau_{t}^{\star}\right)}{h_{t}}, \\
y_{t}^{1} & =\frac{1-\zeta}{1+\beta} h_{t}\left(w_{t}-\tau_{t}\right), & y_{t}^{\star, 1} & =\frac{1-\zeta}{1+\beta}\left(w_{t}^{\star}-\tau_{t}^{\star}\right), \\
x_{t}^{2} & =\zeta\left(1+i_{t}\right)\left(k_{t}+b-\phi_{t}\right), & x_{t}^{\star, 2} & =\zeta\left[\frac{1}{h_{t}}\left(1+i_{t}^{\star}\right)\left(k_{t}^{\star}+b^{\star}\right)+\left(1+i_{t}\right) \phi_{t}\right], \\
y_{t}^{2} & =(1-\zeta) h_{t}\left(1+i_{t}\right)\left(k_{t}+b-\phi_{t}\right), & y_{t}^{\star, 2} & =(1-\zeta)\left[\left(1+i_{t}^{\star}\right)\left(k_{t}^{\star}+b^{\star}\right)+h_{t}\left(1+i_{t}\right) \phi_{t}\right] .
\end{aligned}
$$

Accordingly, Home's trade balance is defined as

$$
x_{t}^{\star, 1}+x_{t}^{\star, 2}-\frac{1}{h_{t}}\left(y_{t}^{1}+y_{t}^{2}\right)
$$

and shows the dependence of the trade balance on the terms of trade.

The motion of Home's net foreign asset position reads as follows:

$$
\phi_{t+1}=\left(1+i_{t}\right) \phi_{t}-\left[x_{t}^{\star, 1}+x_{t}^{\star, 2}-\frac{1}{h_{t}}\left(y_{t}^{1}+y_{t}^{2}\right)\right] .
$$

Multiplying $(16)$ by $h_{t}$ and $\left(16^{\star}\right)$ by $\zeta /(1-\zeta)$, subtracting the second from the first, and inserting optimal consumption of households in Home and Foreign, gives the combined product market clearing condition:

$$
h_{t}\left[M\left(k_{t}\right)^{\alpha_{K}}(S)^{\alpha_{P}}-k_{t+1}\right]=\frac{\zeta}{(1-\zeta)}\left[M\left(k_{t}^{\star}\right)^{\alpha_{K}}\left(S^{\star}\right)^{\alpha_{P}}-k_{t+1}^{\star}\right] .
$$

The expression in square brackets on the left hand side of (23) is Home's net output $\left(\equiv x_{t}-k_{t+1}\right)$ devoted to consumption by domestic and foreign households, and analogously for Foreign on the right hand side. Thus, (23) states that the terms of trade are determined by the proportion of net outputs in Home and Foreign, and by the (exogenously given) expenditure shares for the domestic and the foreign good. If Home's net output decreases more than Foreign's, the terms of trade must increase. 
The dynamic system for the terms of trade, $h_{t}$, and for the capital stocks in Home and Foreign $\left(k_{t+1}\right.$ and $k_{t+1}^{\star}$ respectively) are thus described by Equations (9), (15), and (23).

\subsection{Existence and Stability of Steady States}

A steady state equilibrium of the discrete dynamical system (9), (15) and (23) occurs when $\left(h, k, k^{\star}\right)$ are stationary along the equilibrium path. (9) reduces to:

$$
k^{\star}=\tilde{S} k, \quad \tilde{S} \equiv\left(\frac{S^{*}}{S}\right)^{\frac{\alpha_{P}}{1-\alpha_{K}}} .
$$

Inserting (24) into (23) yields for the steady state terms of trade:

$$
h=\tilde{S} \frac{\zeta}{1-\zeta} .
$$

Inserting (24) and (25) into (15), the following equation determines $k$ :

$$
k+\vartheta(1-\sigma)=M S^{\alpha_{P}} k^{\alpha_{K}-1}\left[\sigma\left(1-\alpha_{K}\right) k-\vartheta \sigma \alpha_{K}\right], \quad \vartheta \equiv \zeta b+(1-\zeta) \tilde{S}^{-1} b^{\star} .
$$

In general, it is not true that for any nonnegative $M, S$, and $\vartheta$, as well as for admissible

$\alpha_{K}, \alpha_{P}$, and $\beta$, a non-trivial solution $0<k<\bar{k}$ exists. $\bar{k}$ is hereby defined as the maximal $k$ such that Home's net output $H(k) \equiv x(k)-k$ is zero, i.e. nothing is left for consumption. The following proposition assures the existence of a finite upper bound of $\vartheta$ and tells us about the number and nature of steady state solutions if $\vartheta$ is less, equal or larger than the upper bound $\bar{\vartheta} .^{7}$

Proposition 1 (Existence of steady states) For any admissible parameter set there exists a $\bar{\vartheta} \in \mathbb{R}_{++}$such that

(i) for $\vartheta<\bar{\vartheta}$ there are one trivial $(k=0)$ and two non-trivial steady states $k^{L}$ and $k^{H}$ with $0<k^{L}<k^{H}<\bar{k}$,

(ii) for $\vartheta=\bar{\vartheta}$ there are one trivial and one non-trivial steady state, and

\footnotetext{
${ }^{7}$ Note that the existence condition is the two-country analogy to Ono $(2002,82)$.
} 
(iii) for $\vartheta>\bar{\vartheta}$ there is only the trivial steady state.

Proof 1 see Appendix A.1.

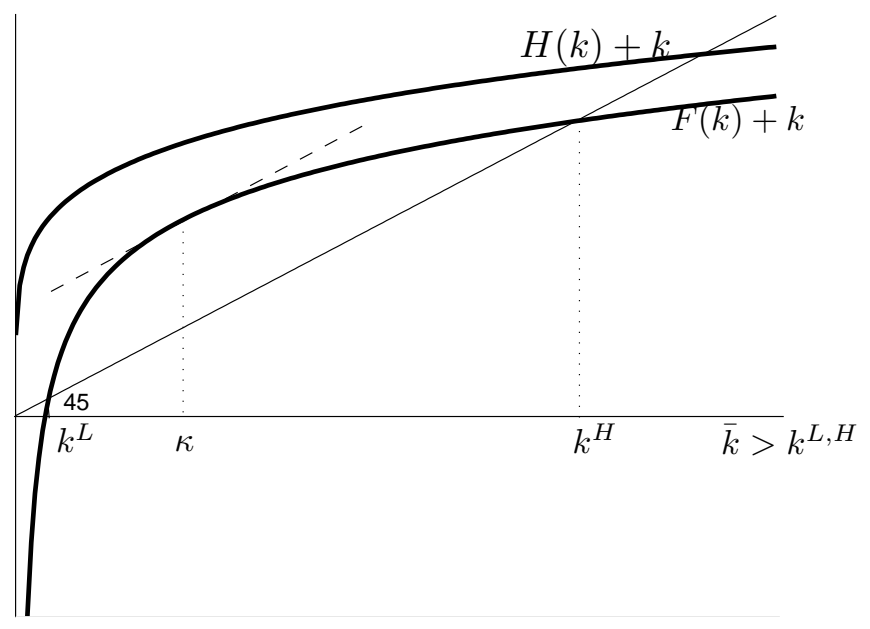

Figure 1: Existence of two distinct steady states $k^{L}$ and $k^{H}$

Figure 1 illustrates the first case of Proposition 1. The graph depicts the relationship $0=F(k) \equiv M S^{\alpha_{P}} k^{\alpha_{K}-1}\left[\sigma\left(1-\alpha_{K}\right) k-\vartheta \sigma \alpha_{K}\right]-\vartheta(1-\sigma)-k$ as implicitly given by (26). Since this function cuts the $45^{\circ}$ line twice, there are two non-trivial steady states, a lower one $k^{L}$, and a higher one $k^{H}{ }^{8}$ If $\vartheta=\bar{\vartheta}$, the graph of $F(k)+k$ were shifted downwards such that the $45^{\circ}$ line is tangential to $F(k)+k$ and hence only one non-trivial steady state exists.

In investigating the stability of the two equilibria, we calculate the eigenvalues $\lambda_{i}$ and the eigenvectors $\mathbf{v}_{\mathbf{i}}=\left(v_{i}^{h}, v_{i}^{k}, v_{i}^{\star}\right)^{T},(i=1,2,3)$ of the Jacobian $J\left(h, k, k^{\star}\right)$ at these two steady states. ${ }^{9}$ For the economically most interesting case $\vartheta<\bar{\vartheta}$, the lower steady state $k^{L}$ is saddle path unstable (therefore we do not explicitly calculate the eigenvectors for this

\footnotetext{
${ }^{8} \kappa$ on the abscissa of the diagram in Figure 1 is needed in the proof of Proposition 1 for ensuring that $F(k)+k$ has unitary slope.

${ }^{9}$ The elements of the Jacobian in the stationary state are given in the Proof of Proposition 2 (see Appendix).
} 
case), while the higher steady state $k^{H}$ is saddle-path stable, i.e. the three eigenvalues are $\lambda_{1}>1, \lambda_{2} \in(0,1)$, and $\lambda_{3} \in(0,1) .{ }^{10}$ This result is summarized in Proposition 2 .

Proposition 2 (Stability of steady states) For $\vartheta<\bar{\vartheta}$, the eigenvalues $\lambda_{i}$ of the Jacobian are given by $\lambda_{1}=(1+i) / \alpha_{K}, \lambda_{2}=\alpha_{K}$, and $\lambda_{3}=\sigma\left(1-\alpha_{K}\right)(1+i)(1+\vartheta / k)$. For $k=k^{L}, \lambda_{1}>1, \lambda_{2} \in(0,1)$, and $\lambda_{3}>1$ and hence $k^{L}$ is saddle path unstable. For $k=k^{H}$, $\lambda_{1}>1, \lambda_{2} \in(0,1)$, and $\lambda_{3}<1$ and hence $k^{H}$ is saddle path stable. The eigenvectors $\mathbf{v}_{\mathbf{i}}=\left(v_{i}^{h}, v_{i}^{k}, v_{i}^{\star}\right)^{T}(i=1,2,3)$ associated with the stable eigenvalues $(i=2,3)$ are:

$$
\mathbf{v}_{2}=\left(-\frac{h}{k}, \frac{1}{\alpha_{K}}+\delta, \tilde{S} \delta\right)^{T}, \quad \mathbf{v}_{3}=(0,1, \tilde{S})^{T}
$$

where $\delta=\frac{\zeta b\left(1-\sigma+\sigma \lambda_{1}\right)}{k\left(\alpha_{K}-\lambda_{3}\right)}$.

Proof 2 see Appendix A.2.

\section{The Effects of Home's Unilateral Permit Reduction on Terms of Trade and Capital Accumulation}

Let us now turn to the initial focus of this paper - the consequences of a unilateral permit reduction for terms of trade and capital accumulation. The repercussions of unilateral climate policy on trade, output and growth are a major concern of policymakers and industry. Effects on output and growth are investigated in several multi-region multi-sector static computable general equilibrium studies. They unanimously find that those countries which unilaterally reduce their climate policies experience declining output leading to macroeconomic contraction (e.g., Fischer and Fox, 2007; Proost and Van Regemorter, 2004; Kuik and Gerlagh, 2003). However, due to their static set-up these models are not suitable to investigate short term and transitional effects of a unilateral permit reduction.

\footnotetext{
${ }^{10}$ If $\vartheta=\bar{\vartheta}$ holds, the dynamic system undergoes a saddle-node bifurcation at a single steady state. The eigenvalues of the Jacobian evaluated at this steady state are as follows: the first is larger than one, the second eigenvalue equals $\alpha_{K}$ and the third is equal to unity.
} 
Regarding the effects on the terms of trade, results are more ambiguous. For instance, Kuik and Gerlagh (2003) find that non-reducing countries can experience a terms of trade deterioration because of the declining import demand by the unilaterally reducing country. If they are, on the other hand, able to increase their exports, their terms of trade can improve. In a model of differentiated climate change policies in the European Union, Proost and Van Regemorter (2004) argue that countries with a high reduction target experience improving terms of trade (while countries with a lower reduction target are confronted with deteriorating terms of trade).

In this section, we intend to deepen the understanding of the transmission channels of unilateral permit reduction in the following way. First, we investigate the transitional and steady state effects of a unilateral permit reduction on the terms of trade and explain them by shifts in the trade balance and in output. By this approach, we are able to distinguish several channels which impact on the terms of trade. Secondly, we analyze the effects on domestic and foreign capital accumulation again in the steady state and during the transition. ${ }^{11}$

To pursue this objective, we assume that Home implements a more stringent permit policy $(S \downarrow)$ in period $t_{0}$ while the permit policy of Foreign remains unchanged at $S^{\star}$. We further assume that the shock is unannounced and permanent, thus ruling out anticipatory behavior on the part of households and firms prior to the shock (e.g., by adjusting their saving decision).

\subsection{Derivation of Transitional and Steady State Effects}

In the shock period, denoted by $t_{0}$, the capital stocks remain at the old steady state value, $k_{t 0}=k^{H}$ and $k_{t 0}^{\star}=k^{\star, H}$. To analyze the impact of a decline in $S$ on the terms of trade during the transition, we approximate the equilibrium paths (9), (15) and (23) linearly

\footnotetext{
${ }^{11}$ Note that effects on foreign capital accumulation are influenced by the assumption of immobile factors of production: production cannot be relocated across countries, but government bonds can.
} 
around the new steady state. The approximation around $\left(h, k, k^{\star}\right)=\left(h^{H}, k^{H}, k^{\star}, H\right)$ yields:

$$
\begin{aligned}
h_{t}=h\left\{1+\frac{\alpha_{K}}{k}\left[\left(k-k_{t}\right)\right.\right. & \left.\left.+\frac{\left(k_{t}^{\star}-k^{\star}\right)}{\tilde{S}}\right]\right\}, \\
k_{t+1}=k_{t}+\alpha_{K}\left[\frac{1-\alpha_{K}}{\alpha_{K}}-\right. & \left.\delta\left(\lambda_{3}-\alpha_{K}\right)\right]\left(k-k_{t}\right)+ \\
& \quad+\left(1+\alpha_{K} \delta\right)\left(\lambda_{3}-\alpha_{K}\right) \frac{\left(k_{t}^{\star}-k^{\star}\right)}{\tilde{S}}, \\
k_{t+1}^{\star}= & k_{t}^{\star}+\alpha_{K}\left[\frac{\left(1-\lambda_{3}\right)}{\alpha_{K}}-\delta\left(\lambda_{3}-\alpha_{K}\right)\right]\left(k^{\star}-k_{t}^{\star}\right)+\alpha_{K} \delta \tilde{S}\left(\lambda_{3}-\alpha_{K}\right)\left(k-k_{t}\right),
\end{aligned}
$$

whereby $k_{0}$ and $k_{0}^{\star}$ are exogenously given, and $\delta$ is defined according to Proposition 2 .

To determine the steady state effects of a marginal reduction of $S$, we totally differentiate (24), (25), and (26), with respect to $S$ :

Proposition 3 (Steady state effects) An infinitesimal change of S leads to a shift of the equilibrium along the gradient given by

$$
\left(\begin{array}{c}
\mathrm{d} h \\
\mathrm{~d} k \\
\mathrm{~d} k^{\star}
\end{array}\right)=\frac{\alpha_{P}}{1-\alpha_{K}}\left(\begin{array}{c}
-h \\
k(1+\gamma) \\
k^{\star} \gamma
\end{array}\right) \frac{\mathrm{d} S}{S}
$$

where $\gamma \equiv \frac{\zeta b\left(1-\sigma+\sigma \lambda_{1} \lambda_{2}\right)}{k\left(1-\lambda_{3}\right)}$ and $\gamma>0$, for $k=k^{H}$.

Proof 3 see Appendix A.6.

\subsection{Effects on Home's Terms of Trade}

We start our discussion by considering the effects on the terms of trade in the shock period before proceeding to the steady state effects. Evaluating (27) at $t=t_{0}$ and the new steady state $\left(h, k, k^{\star}\right)=\left(\hat{h}, \hat{k}, \hat{k^{\star}}\right)$ yields for $h$ in the shock period:

$$
h_{t 0}=\hat{h}\left[1+\alpha_{K} \frac{k_{t 0}}{\hat{k}}\left(\tilde{S}^{-1}-1\right)\right] \text {. }
$$


Knowing that $\alpha_{K} k_{t 0} / \hat{k}$ is less than unity and $\left(\tilde{S}^{-1}-1\right)$ is negative and since the new stationary state value of $h$, denoted by $\hat{h}$, is increased by a reduction in $S, h_{t 0}$ increases, too, but less than $\hat{h}$. Thus, while jumping upwards, $h_{t 0}$ does not overshoot its new steady state value.

To understand this improvement of the terms of trade, assume on the contrary that the terms of trade would not change in the shock period $t_{0}$. Furthermore, it is convenient to assume that in the pre-shock steady state the Golden Rule holds $\left(i=i^{\star}=0\right) .{ }^{12}$ Since the capital stocks are fixed in the shock period, according to (1)-(3), the permit price $e_{t 0}$ increases while the wage rate $w_{t 0}$ and the interest rate $i_{t 0}$ decline. Moreover, domestic output declines while foreign output remains unaffected. Young households experience a reduction in net wages $\left(w_{t 0}-\tau_{t 0}\right)$, and the wealth of old households, $\left(1+i_{t 0}\right)\left(k_{t 0}+b-\phi_{t 0}\right)$, also declines. According to (17)-(20), consumption of the domestic and the foreign good is reduced by Home's young and old household. By similar reasoning in Foreign, young households' consumption of the domestic and the foreign good are unaffected, but old households consume slightly more of the Foreign and the Home good. Since Home's exports increase and her imports sharply fall a surplus arises in Home's trade balance (see (21)). Since, by assumption, Home is a net creditor $\left(\phi_{t 0}<0\right)$, and acknowledging that in the steady state the trade balance is equal to $i \phi$ (see (22)), her trade balance has to become negative. Consequently, Home's terms of trade cannot remain unchanged but have to improve in the shock period to yield a deficit in the trade balance in the new steady $_{\text {state. }}{ }^{13}$

In period $t_{0}+1$, the terms of trade continue to rise. In particular, both capital stocks fall (see next section below for details) and both interest rates rise. But since the permit level remains at its new lower value, the domestic interest rate starts from a lower level than the foreign rate in the shock period (see (1) and $\left(1^{\star}\right)$ ). Hence, it follows from (8) that $h_{t 0+1}>h_{t 0}$. The trade balance continues to deteriorate because Home's exports fall while

\footnotetext{
${ }^{12}$ This assumption is not essential for the argument but eases exposition.

${ }^{13}$ As a consequence of log-linear utility functions, terms of trade elasticities of export and import demand functions are unity and hence the Marshall-Lerner conditions are fulfilled: if the terms of trade increase the trade balance deteriorates.
} 
the imports increase modestly due to the terms of trade improvement and the negative capital stock effect. In the following periods, however, the positive terms of trade effect is dominated by the negative capital stock effect and hence the deficit in the trade balance decreases towards its new steady state value.

Regarding the steady state effects, Proposition 3 states that a permanent decline in the permit volume of Home $(S \downarrow)$, leads to an improvement in the equilibrium terms of trade. This can also be seen from (25) where a reduction in $S$ leads to an increase in $\tilde{S}$ and therefore the terms of trade improve. Investigating (23) reveals that Home's output devoted to domestic and foreign consumption falls by more than in Foreign. Since moreover the expenditure shares for the domestic and the foreign good are exogenously given (zero substitution effect), the terms of trade have to improve. Thus, Home's terms of trade improve both during the transition and in the new steady state, the foreign good in units of the domestic good becomes cheaper. One important observation is, however, that the export shares along with the import shares increase during the transition despite or even because of the fall in domestic output. Thus, absolute quantities of exports, imports and output fall, but because output falls the most, export and import shares increase over time.

\subsection{Effects on Capital Accumulation}

While capital stocks are not affected in the shock period, the capital stocks adjust in the post-shock period $t_{0}+1$. Solving (15) and (23) simultaneously for $k_{t+1}$ and $k_{t+1}^{\star}$, taking the total differentials of Home's and Foreign's capital stocks in $t_{0}+1$ with respect to $S$, and evaluating the total differentials at the initial steady state $\left(h, k, k^{\star}\right)$ yields:

$$
\begin{aligned}
\frac{\mathrm{d} k_{t 0+1}}{\mathrm{~d} S}=\alpha_{P} M( & \left.k_{t 0}\right)^{\alpha_{K}}(S)^{\alpha_{P}-1}\left[\zeta\left(1-\alpha_{K}\right) \sigma+(1-\zeta)\right]+ \\
& +\frac{\zeta}{\left(h_{t 0}\right)^{2}}\left\{M\left(k_{t 0}^{\star}\right)^{\alpha_{K}}\left(S^{\star}\right)^{\alpha_{P}}\left[1-\left(1-\alpha_{K}\right) \sigma\right]+b^{\star}\left(\sigma i_{t 0}^{\star}+1\right)\right\} \frac{\mathrm{d} h_{t 0}}{\mathrm{~d} S}
\end{aligned}
$$




$$
\begin{aligned}
\frac{\mathrm{d} k_{t 0+1}^{\star}}{\mathrm{d} S}=-(1-\zeta) \alpha_{P} M\left(k_{t 0}\right)^{\alpha_{K}}(S)^{\alpha_{P}-1}\left[1-\left(1-\alpha_{K}\right) \sigma\right]- \\
\quad-(1-\zeta)\left\{M\left(k_{t 0}\right)^{\alpha_{K}}(S)^{\alpha_{P}}\left[1-\left(1-\alpha_{K}\right) \sigma\right]+b^{\star}\left(\sigma i_{t 0}+1\right)\right\} \frac{\mathrm{d} h_{t 0}}{\mathrm{~d} S} .
\end{aligned}
$$

Investigating (32) we find two opposing effects: the first positive direct effect increasing the capital stock (holding $h_{t 0}$ fixed), and the second negative effect induced by the fall in the terms of trade $\left(\mathrm{d} h_{t 0} / \mathrm{d} S<0\right)$. However, utilizing the linear approximation of the equilibrium dynamics (28), it is easy to see that the first effect dominates the second since (28) can be reduced to $k_{t 0+1}-k_{t 0}=\left(1-\lambda_{3}\right)\left(k-k_{t 0}\right)$, and $\left(1-\lambda_{3}\right)>0$ and $\mathrm{d} k / \mathrm{d} S>0$. Thus, Home's capital stock declines in the post-shock period as a consequence of a fall in $S$. On the other hand, according to (33), in Foreign the direct effect on the capital stock is negative while the terms of trade effect is positive. Using the linear approximation (29), which can be reduced to $k_{t 0+1}^{\star}-k_{t 0}^{\star}=\left(1-\lambda_{3}\right)\left(k^{\star}-k_{t 0}^{\star}\right)$, it is apparent that the second effect dominates and thus a fall in $S$ leads to a decline in Foreign's capital stock too.

Regarding the steady state effects, a permanent decline in the permit volume of Home $(S \downarrow)$ leads to a decline in both the equilibrium values of $k$ and $k^{\star}$ (see Proposition 3). This can also be seen from (26): since $\vartheta$ decreases along with a decline in $S, k$ has to fall. By inspecting (24), we see that the foreign capital stock is influenced by the increase in $\tilde{S}$ and the fall in $k$, with the net effect being negative according to Proposition 3 since $\gamma>0$. Thus, capital accumulation is also impaired in Foreign, but less than in Home. Intuitively, the capital stocks decline because the $S$ shock reduces steady-state net wages and thereby domestic savings. In order to restore equilibrium, capital stocks in both countries must decrease and the interest rate must increase. Since Home's capital stock falls by more than Foreign's, the steady-state terms of trade have to increase. In other words, unilateral permit reduction causes a reduction in capital accumulation in the post shock period and during the transition towards the new steady state. These can be regarded as the macroeconomic costs of environmental regulation.

It is interesting to observe that a reduction in the capital stocks and in Home's permit volume leads to a reduction in Home's and Foreign's output. The prices of permits increase in Home and the real interest rates increase in both Home and Foreign. Due 
to (8), interest rates are balanced across Home and Foreign. Moreover, the wage rate declines and the transfers to the households fall. As a consequence, in Home, both young household's net income and old household's wealth fall. However, since the terms of trade improve, the foreign good becomes relatively cheaper for Home's households. Thus, by evaluating (17)-(20) at the steady state, we find that young households' consumption of domestic and foreign goods is reduced, as is old households' consumption of the domestic good (but less severely than for the young because the rise in interest payments leads to a modest increase in wealth), while the old households' consumption of the foreign good increases. Thus, a unilateral permit reduction policy leads to a redistribution of wealth from the young to the old households, and this effect is strengthened if Home is a net creditor.

\section{Welfare Effects of a Unilateral Permit Reduction}

From the previous sections we know that a reduction in Home's permit volume has a positive effect on Home's terms of trade but negative consequences on capital accumulation. Hence, the question remains what the net effect of these forces is on domestic and foreign welfare. One might tend to conclude that the net effect for welfare is ambiguous, but we will show that this is not in fact the case. Since the transitional effects lead to rather messy expressions, we focus on the steady state effects before tackling intuitive discussion of transitional impacts.

\subsection{Home's Welfare Effect}

In order to derive the welfare effect on Home of a shock in $S$, we use the indirect intertemporal utility function $U\left(x^{1}, y^{1}, x^{2}, y^{2}\right) \equiv V(w-\tau, 1+i, h)$ evaluated at the initial steady state. After substituting from the household's first order conditions $\partial U / \partial y^{1}=$

$\partial U / \partial x^{1}(h)^{-1}, \partial U / \partial x^{2}=\partial U / \partial x^{1}(1+i)^{-1}, \partial U / \partial y^{2}=\partial U / \partial x^{1}((1+i) h)^{-1}$ and collecting 
similar terms, Home's welfare effect is given by:

$$
\begin{aligned}
& \frac{\mathrm{d} V}{\mathrm{~d} S}=\frac{\partial U}{\partial x^{1}}\left\{\left[\frac{\partial(w-\tau)}{\partial k} \frac{\mathrm{d} k}{\mathrm{~d} S}+\frac{\partial(w-\tau)}{\partial S}\right]+\sigma \frac{w-\tau}{1+i}\left[\frac{\partial(1+i)}{\partial k} \frac{\mathrm{d} k}{\mathrm{~d} S}+\frac{\partial(1+i)}{\partial S}\right]+\right. \\
& \left.+(1-\zeta) \frac{w-\tau}{h} \frac{\mathrm{d} h}{\mathrm{~d} S}\right\}
\end{aligned}
$$

A change in Home's intertemporal welfare can thus be decomposed into a change of the net wage rate, of the interest factor, and of the terms of trade. After computing these derivatives we can determine the sign of these partial effects:

$$
\begin{aligned}
{\left[\frac{\partial(w-\tau)}{\partial k} \frac{\mathrm{d} k}{\mathrm{~d} S}+\frac{\partial(w-\tau)}{\partial S}\right] } & =\frac{\alpha_{P}}{S}[(1+i)(k+b)(1+\gamma)+(w-\tau-b)]>0(34) \\
\sigma \frac{w-\tau}{1+i}\left[\frac{\partial(1+i)}{\partial k} \frac{\mathrm{d} k}{\mathrm{~d} S}+\frac{\partial(1+i)}{\partial S}\right] & =-\sigma \gamma \frac{\alpha_{P}}{S}(w-\tau)<0 \\
(1-\zeta) \frac{w-\tau}{h} \frac{\mathrm{d} h}{\mathrm{~d} S} & =-\frac{(1-\zeta)}{\left(1-\alpha_{K}\right)} \frac{\alpha_{P}}{S}(w-\tau)<0
\end{aligned}
$$

In line with the results for the case of unilateral fiscal expansion by Ono and Shibata (2005), a country's unilateral permit reduction affects its lifetime utility through three channels: the negative wealth effect (34), the positive interest effect (35), and the positive terms of trade effect (36). The first effect, the wealth effect is caused by a decrease in Home's household lifetime net income (see the discussion in the previous section). The second effect is positive (the interest factor increases) and is caused by the reduced capital accumulation. Ono and Shibata $(2005,223)$ call this positive effect a foreign asset or intertemporal macroeconomic effect, since this effect cannot appear in static trade models. ${ }^{14}$ The third effect is the positive terms of trade effect which is familiar from the previous section. The total welfare effect of a unilateral reduction in Home's permit volume $S$ is then given by

$$
\frac{\mathrm{d} V}{\mathrm{~d} S}=\frac{\alpha_{P}(1+\beta)}{S(w-\tau)}\left\{\gamma[(1+i)(k+b)-\sigma(w-\tau)]+\frac{(1+i) k}{\alpha_{K}}-(1-\zeta) \frac{(w-\tau)}{\left(1-\alpha_{K}\right)}\right\} .
$$

For the dynamically efficient case where Home is a net debtor $(\phi>0)$, we are without further assumption able to sign the net welfare effect as unambiguously positive. For the

\footnotetext{
${ }^{14}$ The foreign asset effect does not play any role in our model since in contrast to Ono and Shibata (2005) in our model the terms of trade in Home are independent of the net foreign asset position of Home (see $(25))$.
} 
opposite case of Home being a net creditor, however, the expression in square brackets in (37) is generally negative and hence the net welfare effect can be signed unambiguously only for the case of the Golden Rule (denoted by superscript 0) and if $\sigma^{2}\left(1-\alpha_{K}\right)^{2}<$ $\alpha_{K}<\sigma\left(1-\alpha_{K}\right)$. Hence in both cases a cap on Home's emissions permits reduces steady state net welfare in Home.

\section{Proposition 4 (Home's welfare effect)}

(i) Suppose that $1+i \geq 1$ (dynamic efficiency). Then, for $\phi>0, \mathrm{~d} V / \mathrm{d} S>0$.

(ii) Suppose that, in accordance with Proposition 1, $0<\vartheta<\bar{\vartheta}$ and that there exists a $\vartheta^{0} \in(0, \bar{\vartheta})$ such that $\left(1+i^{0}\right)=\alpha_{K} M\left(k^{0}\right)^{\left(\alpha_{K}-1\right)} S^{\alpha_{P}}=1$ (Golden Rule). Then, for $\phi<0$ and $\sigma^{2}\left(1-\alpha_{K}\right)^{2}<\alpha_{K}<\sigma\left(1-\alpha_{K}\right)$,

$$
\left.\frac{\mathrm{d} V}{\mathrm{~d} S}\right|_{1+i=1}=\frac{\alpha_{P}}{S} \frac{(1+\beta)}{\left(1-\alpha_{K}\right)} \zeta \frac{\left[b \alpha_{K} \phi^{0}+\left(k^{0}\right)^{2}\left(1-\lambda_{3}^{0}\right)\right]}{\left(k^{0}\right)^{2}\left(1-\lambda_{3}^{0}\right)}>0 .
$$

Proof 4 see Appendix A.4.

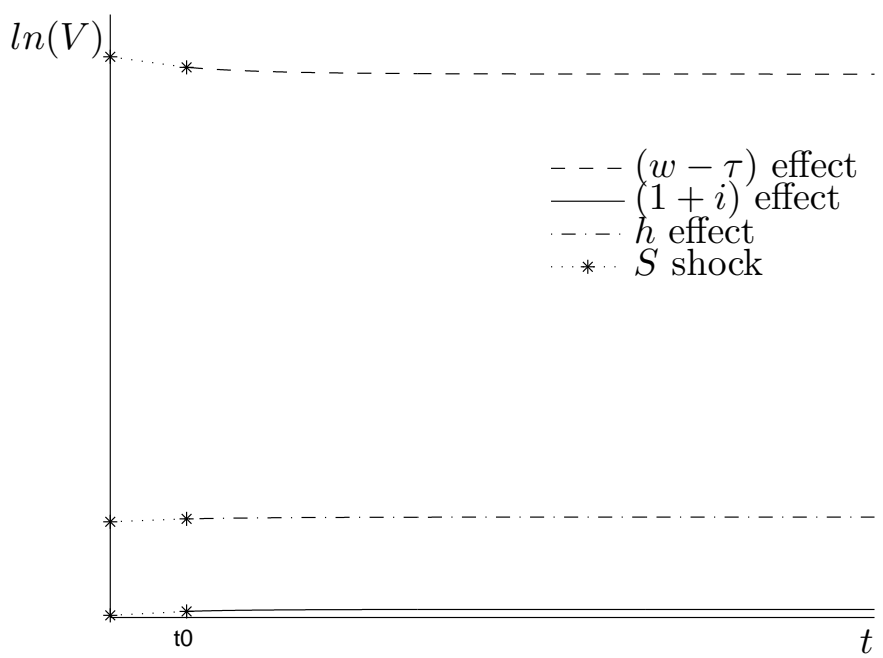

Figure 2: The transitional welfare effect: the wealth, interest, and terms of trade effect 


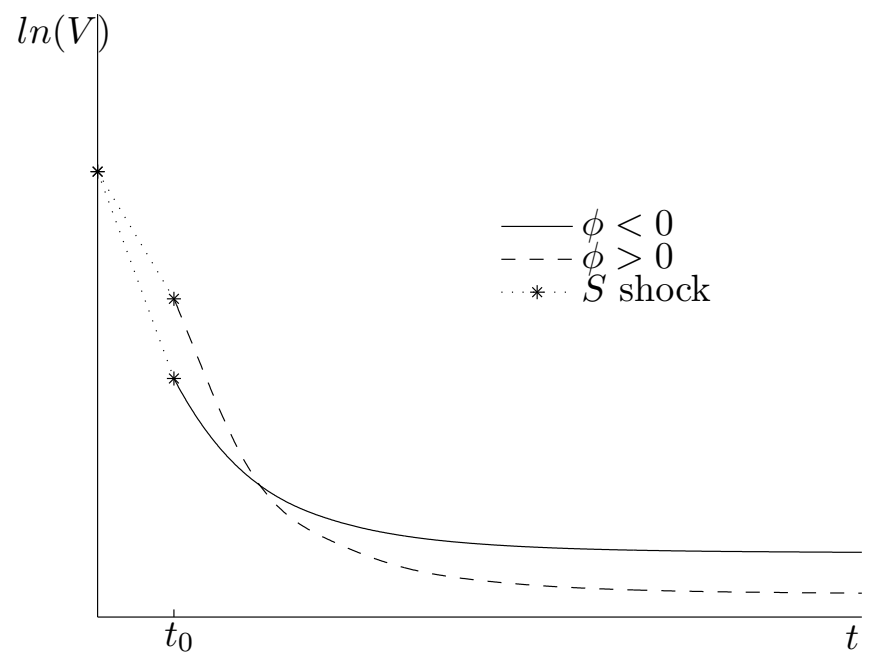

Figure 3: The transitional dynamics effects for Home's welfare: the influence of the net foreign asset position

Let us finally look at the transition towards the new steady state by means of numerical illustration. ${ }^{15}$ Figure 2 decomposes the net welfare efect for Home and shows that the wealth effect caused by an $S$-shock is clearly negative, while both the interest effect and the terms of trade effects are positive. A first important observation is that the wealth effect dominates the other effects (at least for economically plausible parameter values). Secondly, the figure assumes that Home is a net debtor. If on the other hand Home were a net creditor and the initial steady state complied with the Golden Rule (as assumed in (ii) of Proposition 4), then the welfare effect in the shock period is stronger than if Home were a net debtor (see Figure 3). In the new steady state, however, the opposite case applies: the welfare effect is stronger for Home being a net debtor than as a net creditor. Thus, for dynamic efficiency and with Home being a net debtor, as well as for the Golden Rule and Home being a net creditor, a permit reduction in Home leads to a reduction in Home's welfare, both during the transition and in the steady state.

\footnotetext{
${ }^{15}$ The chosen parameter values for Home being a net creditor are as follows: $\beta=0.6, \zeta=0.5, M=5$, $\alpha_{K}=0.3, \alpha_{P}=0.1, S=S^{\star}=1, b=0.1, b^{\star}=0.4$. For the net debtor case, values of $b$ and $b^{\star}$ are permuted. To simulate the $S$ shock, Home's permit volume is reduced by 0.1 . MATLAB is used to numerically solve the dynamic system and to plot the graphs.
} 


\subsection{Foreign's Welfare Effect}

Proceeding similarly as for Home, we derive the steady-state welfare effect for Foreign as:

$$
\frac{\mathrm{d} V^{\star}}{\mathrm{d} S}=\frac{\partial U^{\star}}{\partial y^{\star, 1}}\left\{\frac{\partial\left(w^{\star}-\tau^{\star}\right)}{\partial k^{\star}} \frac{\mathrm{d} k^{\star}}{\mathrm{d} S}+\sigma \frac{\left(w^{\star}-\tau^{\star}\right)}{\left(1+i^{\star}\right)} \frac{\partial\left(1+i^{\star}\right)}{\partial k^{\star}} \frac{\mathrm{d} k^{\star}}{\mathrm{d} S}-\zeta \frac{\left(w^{\star}-\tau^{\star}\right)}{h} \frac{\mathrm{d} h}{\mathrm{~d} S}\right\} .
$$

where

$$
\begin{aligned}
\frac{\partial\left(w^{\star}-\tau^{\star}\right)}{\partial k^{\star}} \frac{\mathrm{d} k^{\star}}{\mathrm{d} S} & =\frac{\alpha_{P}}{S^{\star}}\left[\left(1+i^{\star}\right)\left(k^{\star}+b^{\star}\right)(1+\gamma)\right]>0, \\
\sigma \frac{\left(w^{\star}-\tau^{\star}\right)}{\left(1+i^{\star}\right)} \frac{\partial\left(1+i^{\star}\right)}{\partial k^{\star}} \frac{\mathrm{d} k^{\star}}{\mathrm{d} S} & =-\sigma(1+\gamma) \frac{\alpha_{P}}{S^{\star}}\left(w^{\star}-\tau^{\star}\right)<0, \\
-\zeta \frac{\left(w^{\star}-\tau^{\star}\right)}{h} \frac{\mathrm{d} h}{\mathrm{~d} S} & =\frac{\zeta}{\left(1-\alpha_{K}\right)} \frac{\alpha_{P}}{S^{\star}}\left(w^{\star}-\tau^{\star}\right)>0 .
\end{aligned}
$$

and, after acknowledging that $i=i^{\star}$ in the steady state:

$$
\frac{\mathrm{d} V^{\star}}{\mathrm{d} S}=\frac{\alpha_{P}(1+\beta)}{S\left(w^{\star}-\tau^{\star}\right)}\left\{\gamma\left[(1+i)\left(k^{\star}+b^{\star}\right)-\sigma\left(w^{\star}-\tau^{\star}\right)\right]+\zeta \frac{\left(w^{\star}-\tau^{\star}\right)}{\left(1-\alpha_{K}\right)}\right\} .
$$

While the structure of the wealth effect is equivalent as to that in Home, the direct effects on $\left(w^{\star}-\tau^{\star}\right)$ and $\left(1+i^{\star}\right)$ are absent and Foreign's terms of trade, $1 / h$, deteriorate. To determine the sign of the total Foreign welfare effect we distinguish again by Foreign's net foreign asset position. If Foreign is a net debtor $\left(\phi^{\star}>0\right)$, Foreign's welfare, without any further assumption, unambiguously declines with reduced $S$. In the opposite case, if Foreign is a net creditor $\left(\phi^{\star}<0\right)$, we have to restrict our result to the case of the Golden Rule and the restriction on the factor elasticity of capital.

\section{Proposition 5 (Foreign's welfare effect)}

(i) Suppose that $1+i^{\star}=1+i \geq 1$ (dynamic efficiency). Then, for $\phi^{\star}=-h \phi>0$, $\mathrm{d} V^{\star} / \mathrm{d} S>0$.

(ii) Suppose that, in accordance with Proposition 1, $0<\vartheta<\bar{\vartheta}$ and that there exists a $\vartheta^{0} \in(0, \bar{\vartheta})$ such that $\left(1+\left(i^{\star}\right)^{0}\right)=\alpha_{K} M\left(\left(k^{\star}\right)^{0}\right)^{\left(\alpha_{K}-1\right)} S^{\alpha_{P}}=1$ (Golden Rule). Then, for $\phi>0$ and $\sigma^{2}\left(1-\alpha_{K}\right)^{2}<\alpha_{K}<\sigma\left(1-\alpha_{K}\right)$,

$$
\left.\frac{\mathrm{d} V^{\star}}{\mathrm{d} S}\right|_{1+i^{\star}=1}=\frac{\alpha_{P}}{S} \frac{(1+\beta)}{\left(1-\alpha_{K}\right)} \zeta \frac{\left[-b \alpha_{K} \phi^{0}+\left(k^{0}\right)^{2}\left(1-\lambda_{3}^{0}\right)\right]}{\left(k^{0}\right)^{2}\left(1-\lambda_{3}^{0}\right)}>0 .
$$


Proof 5 see Appendix A.5

The economic significance of this is clear. Even if the foreign country refuses to implement a more stringent permit policy she loses in terms of economic welfare, while the country implementing a restrictive policy can pass on part of the negative welfare effects to other economies. Moreover, this spillover effect is stronger if the country is a large open economy because of the influence on the terms of trade, than if the country is a small open or a closed economy.

\subsection{Comparing the Welfare Effects of Home and Foreign}

It now remains to be investigated which country is exposed to larger welfare losses. As before, we will investigate the cases separately for $\phi>0$ and $\phi<0$. We furthermore restrict the analysis to the case of dynamic efficiency, i.e. $1+i \geq 1,1+i^{\star} \geq 1$. Proposition 6 verifies that the relative magnitude of the welfare effects in Home compared to Foreign depends on the net foreign asset position of the countries.

Proposition 6 (Relative magnitude of welfare effect) Suppose that $1+i \geq 1$ (dynamic efficiency). Then,

$$
\frac{\mathrm{d} V}{\mathrm{~d} S}-\frac{\mathrm{d} V^{\star}}{\mathrm{d} S}=\frac{\alpha_{P}}{S}(1+\beta) \frac{(1+i)}{(w-\tau)} \Delta
$$

where

$$
\Delta \equiv \gamma \phi\left[1+h \frac{(w-\tau)}{\left(w^{\star}-\tau^{\star}\right)}\right]+b \frac{i}{(1+i)}
$$

Depending on the sign of $\phi$, two cases emerge:

(i) For $\phi>0 \Longleftrightarrow \phi^{\star}<0$,

$$
\frac{\mathrm{d} V^{\star}}{\mathrm{d} S}<\frac{\mathrm{d} V}{\mathrm{~d} S}
$$

(ii) For $\phi<0 \Longleftrightarrow \phi^{\star}>0$, and the Golden Rule case, where $1+i=1+i^{\star}=1$,

$$
\left.\frac{\mathrm{d} V^{\star}}{\mathrm{d} S}\right|_{1+i=1}>\left.\frac{\mathrm{d} V}{\mathrm{~d} S}\right|_{1+i=1} .
$$


Proof 6 see Appendix A.6.

Consequently, if Home is a net debtor and Foreign a net creditor, the effect of Home's permit policy on Foreign's welfare is certainly smaller than on Home's welfare. However, where Foreign is a net debtor and the Golden Rule applies, the reverse case emerges, with stronger welfare effects for Foreign than for Home.

To illustrate the economic rationale for these results assume that we start from the Golden Rule in which the interest rate is zero. Through the $S$ shock the interest rate becomes larger than zero. Then, if Home is a net debtor, i.e. $\phi>0$, the wealth of Home's households falls by the interest payment on foreign debt and hence Home's welfare loss exceeds Foreign's. On the other hand, if Foreign is a net debtor, i.e. $\phi^{\star}>0$, wealth of Home's household rises by the interest payments on the credit to Foreign, and hence Foreign's welfare loss exceeds Home's.

\section{$5 \quad$ Summary and Conclusions}

This paper investigates the effects of a unilateral reduction in emission permits on terms of trade, capital accumulation and welfare in a two-good, two-country OLG model. We first derive the intertemporal equilibrium dynamics of the terms of trade, and of Home's and Foreign's capital stocks. The system exhibits in general two steady state solutions of which the one associated with higher capital stocks in Home and Foreign is saddle path stable.

When Home unilaterally reduces the cap on emissions, the terms of trade of the domestic economy immediately jump upwards and continue to increase along the stable manifold towards the new steady state. As a consequence, the purchasing power of domestic households increases. With rising terms of trade, however, capital stocks are reduced in both countries, but the contractionary effect is stronger in the country which reduces the 
permit level. Thus, while both countries grow more slowly than without a more stringent climate policy, domestic economic growth is affected more strongly.

To evaluate the net effect of rising terms of trade and falling capital stocks, we investigate the welfare effect by deriving the total differential of the indirect intertemporal utility function with respect to the number of permits distributed in Home. While the terms of trade improvement is welfare enhancing, a more stringent permit policy also has welfare consequences via factor prices: the wage rate declines, while the interest rate and the permit price increase. In line with the literature, we call these partial effects the terms of trade effect, the interest effect and the wealth effect. Our first important result is that the total domestic welfare effect of a reduction in Home's emission permits level is negative but that the strength of the welfare decline is weaker (stronger) if Home is a net creditor (debtor).

For Foreign, similar effects emerge: i.e. a terms of trade, a wealth, and an interest effect. Two important differences compared to Home are that there is no direct effect of the permit reduction (only indirect effects through capital stock adjustments), and that the terms of trade effect is negative because Foreign's terms of trade deteriorate. In analogy to Home, Foreign's total welfare effect is negative and the welfare decline is stronger if Foreign is a net debtor and Home consequently a net creditor.

Our second important result emerges when comparing the relative strength of the welfare decline between Home and Foreign caused by a reduction of Home's permits. If Home is a net creditor and Foreign thus a net debtor, welfare in Foreign declines more than in Home. Thus, there is not only an international spillover effect induced by Home's unilateral policy, this spillover effect can also be stronger than the domestic effect. The intuition for this result lies in the openness to international trade: if a country's economy is closed, then all of the effects of a permit reduction are domestic while an open economy shares some of the costs (in terms of reduced capital accumulation and welfare) with trading partners. If, moreover, the country is a large economy, as in our model, it can influence the terms of trade (which improve) leading to additional scope for international spillover. 
Some interesting lessons can be drawn from our theoretical analysis. First, a unilateral reduction in emission permits has positive consequences for terms of trade and interest rates in the reducing country. Analyzing the total welfare effect reveals, however, that contractionary forces of reduced capital accumulation outweigh these positive effects. Thus, attempts to mitigate climate change lead to intertemporal welfare losses, delivering an obvious explanation for why climate policy has only been implemented with great hesitation in the past.

Second, welfare losses for the country which unilaterally reduces its emission permits differ. They are smaller for large net creditor countries (like the European Union and many other industrialized regions) than for net debtor countries (like the United States). Thus, the European Union as a large net creditor to the world economy can restrict carbon emission more easily than if it were a net debtor.

Third, and most important, if the country which unilaterally reduces her emission permits is a net creditor, her own welfare loss remains below that of the non-reducing country. The policy implication of this last result is clear: even if the United States decides not to set a stricter cap on its emissions, but the European Union does, the United States experiences larger welfare losses. It should therefore be in the United States' interest to agree on an internationally coordinated climate policy, particular in regard to the European Union and other Annex-I countries.

There are several routes available for future research. International trade could be enriched in our model by having production of both goods in each country. Furthermore, we could examine the influence of unilateral permit reduction in one country on emissions in the other country to address carbon leakage and international policy interaction. Another extensions of our study would consist of a comparison between alternative permit systems or of complementary policies to reduce welfare losses, like border tax adjustments. 


\section{References}

Babiker, Mustafa H. (2005). Climate change policy, market structure, and carbon leakage. Journal of International Economics 65, 421-445.

Bhagwati, J. (1958). Immiserizing growth: a geometrical note. Review of Economic Studies $\mathbf{x x}, 201-5$.

Chen, Zhiqi (1992). Long-run equilibria in a dynamic Heckscher-Ohlin model. Canadian Journal of Economics 25(4), 923-43.

Copeland, Brian R. and M. Scott Taylor (2005). Free trade and global warming: a trade theory view of the Kyoto Protocol. Journal of Environmental Economics and Management 49, 205-234.

Diamond, Peter (1965). National debt in a neoclassical growth model. American Economic Review 55, 1126-1150.

Fischer, Carolyn and Alan K. Fox (2007). Output-based allocation of emission permits for mitigating tax and trade interactions. Energy Journal 24, 97-120.

Frenkel, Jacob A. and Assif Razin (1986). The international transmission and effects of fiscal policies. American Economic Review 76, 330-335.

Gosh, Atish R. (1992). Fiscal policy, the terms of trade and the external balance. Journal of International Economics 33, 105-25.

Grubb, Michael and Karsten Neuhoff (2006). Allocation and competitiveness in the EU emissions trading scheme: policy overview. Climate Policy 6, 7-30.

Hoel, Michael (1991). Global environmental problems: The effects of unilateral actions taken by one country. Journal of Environmental Economics and Management 20, 55-70.

Jouvet, Pierre-André, Philippe Michel and Gilles Rotillon (2005a). Equilibrium with a market of permits. Research in Economics 59, 148-163. 
Jouvet, Pierre-André, Philippe Michel and Gilles Rotillon (2005b). Optimal growth with pollution: how to use pollution permits?. Journal of Economic Dynamics and Control 29(9), 1597-1609.

Kuik, Onno and Reyer Gerlagh (2003). Trade liberalization and carbon leakage. Energy Journal 24, 97-120.

Lipton, David and Jeffrey Sachs (1983). Accumulation and growth in a two-country model. Journal of International Economics 15(1-2), 135-159.

Obstfeld, Maurice (1989). Fiscal deficits and relative prices in a growing world economy. Journal of Monetary Economics 23, 461-84.

Ono, Tetsuo (2002). The effects of emission permits on growth and the environment. Environmental and Resource Economics 21, 75-87.

Ono, Yoshiyasu and Akihisa Shibata (2005). Fiscal spending, relative-price dynamics, and welfare in a world economy. Review of International Economics 13(2), 216-236.

Persson, Torsten (1985). Deficits and intergenerational welfare in open economies. Journal of International Economics 19(1-2), 67-84.

Proost, Stef and Denise Van Regemorter (2004). Climate change policy in European countries and its effects on industry. Mitigation and Adaptation Strategies for Global Change 9, 453-475.

Van Asselt, Harro and Frank Biermann (2007). European emissions trading and the international competitiveness of energy-intensive industries: a legal and political evaluation of possible supporting measures. Energy Policy 35, 497-506.

Zee, Howell H. (1987). Government debt, capital accumulation, and the terms of trade in a model of interdependent economies. Economic Inquiry 25, 599-618. 


\section{A Appendix}

\section{A.1 Proof of Proposition 1}

Let $\phi(\vartheta) \equiv F(K(\vartheta), \vartheta)$ whereby $K(\vartheta)$ is the solution of the equation $F_{k}(k, \vartheta)=0$ for a given value of $\vartheta$. Since (i) $F_{k}(k, \vartheta)$ is a continuous and strictly decreasing function, (ii) $\lim _{k \rightarrow 0} F_{k}(k, \vartheta)=$ $\infty$, and (iii) $\lim _{k \rightarrow \infty} F_{k}(k, \vartheta)=-1$, an intermediate value theorem ensures for each $\vartheta$ the existence of a $\kappa$ which solves $F_{k}(k, \vartheta)=0$. Moreover, the solution is unique since $F_{k k}(k, \vartheta)<0$. Hence, $\kappa=K(\vartheta)$. Note also that $K(\vartheta)$ is a strictly increasing function because $F_{k k}(k, \vartheta)<0$ and $F_{k \vartheta}(k, \vartheta)>0$. Since $F_{\vartheta}(k, \vartheta)<0$, an envelope theorem implies that $\phi(\vartheta)$ is a strictly decreasing function with $\phi(0)>0$ and $\lim _{\vartheta \rightarrow \infty} \phi(\vartheta)<0$. Continuity of $\phi(\vartheta)$ implies the existence of $\bar{\vartheta}$ such that $\phi(\bar{\vartheta})=0$. For $\vartheta \in[0, \bar{\vartheta}), \phi(\vartheta)>0$, while $\phi(\vartheta)<0$ for $\vartheta \in[\bar{\vartheta}, \infty)$.

\section{A.2 Proof of Proposition 2}

In order to get information about the stability of the two non-trivial steady states (see Proposition 1), we calculate the eigenvalues of the Jacobian of the system (9), (15) and (23) in the steady state $\left(h, k, k^{\star}\right)$ :

$$
\left.\mathbf{J}\right|_{\left(h, k, k^{\star}\right)}=\left.\left(\begin{array}{ccc}
j_{11} & j_{12} & j_{13} \\
j_{21} & j_{22} & j_{23} \\
j_{31} & j_{32} & j_{33}
\end{array}\right)\right|_{\left(h, k, k^{\star}\right)}
$$

where

$$
\begin{aligned}
& j_{11}=\frac{\partial h_{t+1}}{\partial h_{t}}=1+\left(1-\alpha_{K}\right) \frac{H}{k}, \\
& j_{12}=\frac{\partial h_{t+1}}{\partial k_{t}}=\frac{\left(1-\alpha_{K}\right)(1+i) h}{k}, \\
& j_{13}=\frac{\partial k_{t+1}}{\partial k_{t}^{\star}}=-\frac{\left(1-\alpha_{K}\right)(1+i) h}{k^{\star}} \\
& j_{21}=\frac{\partial k_{t+1}}{\partial h_{t}}=\frac{(1-\zeta) H-\zeta \phi}{h}, \\
& j_{22}=\frac{\partial k_{t+1}}{\partial k_{t}}=(1+i)\left[1-\zeta+\zeta \sigma\left(1-\alpha_{K}\right)\left(1+\frac{b}{k}\right)\right],
\end{aligned}
$$




$$
\begin{aligned}
& j_{23}=\frac{\partial k_{t+1}}{\partial k_{t}^{\star}}=-(1-\zeta)(1+i) \tilde{S}^{-1}\left[1-\sigma\left(1-\alpha_{K}\right)\left(1+\frac{b^{\star}}{k^{\star}}\right)\right], \\
& j_{31}=\frac{\partial k_{t+1}^{\star}}{\partial h_{t}}=\frac{\zeta}{h} \tilde{S}(H+\phi), \\
& j_{32}=\frac{\partial k_{t+1}^{\star}}{\partial k_{t}}=-\zeta(1+i) \tilde{S}\left[1-\sigma\left(1-\alpha_{K}\right)\left(1+\frac{b}{k}\right)\right], \\
& j_{33}=\frac{\partial k_{t+1}^{\star}}{\partial k_{t}^{\star}}=(1+i)\left[\zeta+(1-\zeta) \sigma\left(1-\alpha_{K}\right)\left(1+\frac{b^{\star}}{k^{\star}}\right)\right],
\end{aligned}
$$

and $H \equiv H(k)=\frac{1+i}{\alpha_{K}} k-k$.

To calculate the eigenvectors and eigenvalues of $J$ we write down the determining equation $\left(J-\lambda_{i} I\right) \mathbf{v}_{i}=0$ as follows (where $I$ denotes the identity matrix):

$$
\left(J-\lambda_{i} I\right) \mathbf{v}_{i}=\left(\begin{array}{ccc}
j_{11}-\lambda_{i} & j_{12} & j_{13} \\
j_{21} & j_{22}-\lambda_{i} & j_{23} \\
j_{31} & j_{32}-\lambda_{i} & j_{33}-\lambda_{i}
\end{array}\right)\left(\begin{array}{c}
v_{i}^{h} \\
v_{i}^{k} \\
v_{i}^{\star}
\end{array}\right)=\left(\begin{array}{l}
0 \\
0 \\
0
\end{array}\right)
$$

Subtracting the second row $\tilde{S}$ times from the first row and multiplying the first row by $k /\left(1-\alpha_{K}\right)$ yields the following equivalent equation

$$
\left(\begin{array}{ccc}
\frac{k}{\left(1-\alpha_{K}\right)}\left(1-\lambda_{i}\right)+H & (1+i) h & -(1+i) h \tilde{S}^{-1} \\
j_{21} & j_{22}-\lambda_{i} & j_{23} \\
-\frac{\tilde{S} H}{h} & \tilde{S}\left[\lambda_{i}-(1+i)\right] & (1+i)-\lambda_{i}
\end{array}\right)\left(\begin{array}{c}
v_{i}^{h} \\
v_{i}^{k} \\
v_{i}^{\star}
\end{array}\right)=\left(\begin{array}{l}
0 \\
0 \\
0
\end{array}\right) .
$$

Adding the first row $\frac{1}{h} \tilde{S}$ times to the last row we get

$$
\left(\begin{array}{ccc}
\frac{k}{\left(1-\alpha_{K}\right)}\left(1-\lambda_{i}\right)+H & (1+i) h & -(1+i) h \tilde{S}^{-1} \\
j_{21} & j_{22}-\lambda_{i} & j_{23} \\
\frac{k \tilde{S}\left(1-\lambda_{i}\right)}{\left(1-\alpha_{K}\right) h} & \tilde{S} \lambda_{i} & -\lambda_{i}
\end{array}\right)\left(\begin{array}{c}
v_{i}^{h} \\
v_{i}^{k} \\
v_{i}^{\star}
\end{array}\right)=\left(\begin{array}{c}
0 \\
0 \\
0
\end{array}\right) .
$$

Finally subtracting the third row $\tilde{S}^{-1} \frac{(1+i) h}{\lambda_{i}}$ times from the first row leads to

$$
\left(\begin{array}{ccc}
\tilde{j_{11}} & 0 & 0 \\
j_{21} & j_{22}-\lambda_{i} & j_{23} \\
\frac{k \tilde{S}\left(1-\lambda_{i}\right)}{\left(1-\alpha_{K}\right) h} & \tilde{S} \lambda_{i} & -\lambda_{i}
\end{array}\right)\left(\begin{array}{c}
v_{i}^{h} \\
v_{i}^{k} \\
v_{i}^{\star}
\end{array}\right)=\left(\begin{array}{l}
0 \\
0 \\
0
\end{array}\right)
$$

with $\tilde{j_{11}}=H+\frac{\left(1-\lambda_{i}\right) k}{\left(1-\alpha_{K}\right.}\left[1-\frac{1+i}{\lambda_{i}}\right]$. Equation (44) can be solved if and only if the determinant of its matrix vanishes, i.e. if either

$$
\left|\begin{array}{cc}
j_{22}-\lambda_{i} & j_{23} \\
\tilde{S} & -1
\end{array}\right|=0
$$




$$
\tilde{j_{11}}=0
$$

Case I Using the definition of $j_{22}$ and $j_{23}$, equation (45) straightforwardly leads to

$$
\lambda_{3}=j_{22}+\tilde{S} j_{23}=(1+i) \sigma\left(1-\alpha_{K}\right)\left[1+\frac{\vartheta}{k}\right] .
$$

To determine its corresponding eigenvector, we use (44). Because of $\tilde{j_{11}} \neq 0$, it follows that $v_{3}^{h}=0$, and thus $(44)$

$$
\left(\begin{array}{cc}
\left(j_{22}-\lambda_{3}\right) & j_{23} \\
\tilde{S} \lambda_{3} & -\lambda_{3}
\end{array}\right)\left(\begin{array}{l}
v_{3}^{k} \\
v_{3}^{\star}
\end{array}\right)=\left(\begin{array}{l}
0 \\
0
\end{array}\right),
$$

with the stated solution as can be seen as follows: The first row leads to $v_{3}^{\star}=\tilde{S} v_{3}^{k}$ and the second row is then solved identically due to the value of $\lambda_{3}$, i.e. we can choose $v_{3}^{k}=1$.

Case II From equation (45') we know that $\tilde{j_{11}}=0$ if and only if

$$
\frac{H}{k}+\frac{\left(1-\lambda_{i}\right)}{\left(1-\alpha_{K}\right.}\left[1-\frac{1+i}{\lambda_{i}}\right]=0
$$

Since $H / k=(1+i) / \alpha_{K}-1$, it follows from (46) that the eigenvalues are $\lambda_{1}=(1+i) / \alpha_{K}>$ 1 and $\lambda_{2}=\alpha_{K}$.

The corresponding eigenvector to $\lambda_{2}=\alpha_{K}$ can be found as follows: $\tilde{j}_{11}=0$ implies that $v_{2}^{h}$ can be chosen freely, so for instance take $v_{2}^{h}=\frac{h}{k}$. Therefore (44) reduces to

$$
\left(\begin{array}{cc}
\left(j_{22}-\alpha_{K}\right) & j_{23} \\
\tilde{S} \alpha_{K} & -\alpha_{K}
\end{array}\right)\left(\begin{array}{c}
v_{2}^{k} \\
v_{2}^{\star}
\end{array}\right)=\left(\begin{array}{c}
-j_{21} \frac{h}{k} \\
-\tilde{S}
\end{array}\right),
$$

The second row yields $v_{2}^{\star}=\tilde{S}\left(v_{2}^{k}+\frac{1}{\alpha_{K}}\right)$. The first row yields

$$
\left(j_{22}-\alpha_{K}\right) v_{2}^{k}+j_{23} \tilde{S}\left(v_{2}^{k}+\frac{1}{\alpha_{K}}\right)=-j_{21} \frac{h}{k}
$$

after substituting for the third eigenvalue $\lambda_{3}=(1+i) \sigma\left(1-\alpha_{K}\right)[1+\vartheta / k]$, the second element of the second eigenvector is

$$
v_{2}^{k}=\frac{1-\lambda_{3} / k+\zeta b / k\left[1-\sigma+(1+i) \sigma / \alpha_{K}\right]}{\lambda_{3}-\alpha_{K}} .
$$




\section{A.3 Proof of Proposition 3}

The total differential of (24), (25), and (26), with respect to $S$ using

$$
\frac{\mathrm{d}}{\mathrm{d} \tilde{S}}=\frac{\mathrm{d} S}{\mathrm{~d} \tilde{S}} \frac{\mathrm{d}}{\mathrm{d} S}=\frac{\alpha_{K}-1}{\alpha_{P}} \frac{S}{\tilde{S}} \frac{\mathrm{d}}{\mathrm{d} S}
$$

can be calculated as follows:

$$
\begin{aligned}
\frac{\mathrm{d} h}{\mathrm{~d} \tilde{S}} & =\frac{\zeta}{1-\zeta}=\frac{h}{\tilde{S}}, \\
\frac{\mathrm{d} k^{\star}}{\mathrm{d} \tilde{S}} & =k+\tilde{S} \frac{\mathrm{d} k}{\mathrm{~d} \tilde{S}} .
\end{aligned}
$$

Differentiation of (26) with respect to $\tilde{S}$ yields

$$
\frac{\tilde{S}}{k} \frac{d k}{d \tilde{S}}=\frac{A}{B}
$$

where

$$
\begin{aligned}
A & =\vartheta \sigma \alpha_{K}\left(1-\alpha_{K}\right) \lambda_{1}-\sigma\left(1-\alpha_{K}\right)^{2} k \lambda_{1}+(1-\zeta) \frac{b^{\star}}{\tilde{S}}(1-\sigma)+(1-\zeta) \frac{b^{\star}}{\tilde{S}} \sigma \alpha_{K} \lambda_{1} \\
B & =k-\vartheta \sigma \alpha_{K} \lambda_{1} k\left(1-\alpha_{K}\right)-\sigma\left(1-\alpha_{K}\right) k \lambda_{1} \alpha_{K} .
\end{aligned}
$$

(26) can be used to simplify $A$ and $\lambda_{3}$ (for its derivation, see Proposition 2) to simplify $B$ as follows:

$$
\begin{aligned}
A & =-\left(1-\alpha_{K}\right)(k+\vartheta(1-\sigma))+(1-\zeta) \frac{b^{\star}}{\tilde{S}}\left(1-\sigma+\sigma \alpha_{K} \lambda_{1}\right) \\
& =\vartheta\left(1-\sigma+\sigma \alpha_{K} \lambda_{1}\right)-\left(1-\alpha_{K}\right) \vartheta(1-\sigma)-\left(1-\alpha_{K}\right) k-\zeta b\left(1-\sigma+\sigma \alpha_{K} \lambda_{1}\right) \\
& =\vartheta \sigma \alpha_{K} \lambda_{1}+\alpha_{K}(k+\vartheta(1-\sigma))-k-\zeta b\left(1-\sigma+\sigma \alpha_{K} \lambda_{1}\right) \\
& =\sigma \alpha_{K}\left(1-\alpha_{K}\right) \lambda_{1}(\vartheta+k)-k-\zeta b\left(1-\sigma+\sigma \alpha_{K} \lambda_{1}\right) \\
& =k\left(\lambda_{3}-1\right)-\zeta b\left(1-\sigma+\sigma \alpha_{K} \lambda_{1}\right), \\
B & =k-\sigma \alpha_{K}\left(1-\alpha_{K}\right) \lambda_{1}(\vartheta+k)=k\left(1-\lambda_{3}\right),
\end{aligned}
$$

and hence

$$
\frac{\tilde{S}}{k} \frac{\mathrm{d} k}{\mathrm{~d} \tilde{S}}=-\left(1+\frac{\zeta b\left(1-\sigma+\sigma \lambda_{1} \lambda_{2}\right)}{k\left(1-\lambda_{3}\right)}\right) .
$$

Using the auxiliary function $\gamma$, equations (47)-(49) can be summarized in vector notation :

$$
\left(\begin{array}{c}
d h \\
d k \\
d k^{\star}
\end{array}\right)=\left(\begin{array}{c}
\frac{h}{\tilde{S}} \\
-\frac{k}{\tilde{S}}(1+\gamma) \\
-\gamma k
\end{array}\right) d \tilde{S}=\frac{\alpha_{P}}{1-\alpha_{K}} \frac{\tilde{S}}{S}\left(\begin{array}{c}
-\frac{h}{\tilde{S}} \\
\frac{k}{\tilde{S}}(1+\gamma) \\
\gamma k
\end{array}\right) d S
$$

which brings forth the stated result. 


\section{A.4 Proof of Proposition 4}

(i) For $\phi>0$, i.e. $k+b-s=\phi>0$ we get $(1+i)(k+b)>k+b>s=\sigma(w-t)$. Therefore, using (37) and acknowledging that $(w-\tau)=\left(\left(1-\alpha_{K}\right) / \alpha_{K}\right) k-b i$,

$$
\begin{aligned}
&\left.\frac{\mathrm{d} V}{\mathrm{~d} S}\right|_{\phi>0} \geq \frac{\alpha_{P}(1+\beta)}{S(w-\tau)}\left\{\frac{(1+i) k}{\alpha_{K}}-(1-\zeta) \frac{(w-\tau)}{\left(1-\alpha_{K}\right)}\right\} \\
&=\frac{\alpha_{P}(1+\beta)}{S(w-\tau)}\left\{\zeta \frac{(1+i) k}{\alpha_{K}}+(1-\zeta) \frac{b i}{\left(1-\alpha_{K}\right)}\right\}>0 .
\end{aligned}
$$

(ii) At the Golden Rule, denoted by 0 , the net wage is given by $\left(w^{0}-\tau^{0}\right)=\left(\left(1-\alpha_{K}\right) / \alpha_{K}\right) k^{0}$. Then, $\mathrm{d} V /\left.\mathrm{d} S\right|_{1+i=1}$ simplifies to:

$$
\left.\frac{\mathrm{d} V}{\mathrm{~d} S}\right|_{1+i=1}=\frac{\alpha_{P}}{S} \frac{(1+\beta)}{\left(w^{0}-\tau^{0}\right)}\left\{\gamma^{0} \phi^{0}+\zeta \frac{k^{0}}{\alpha_{K}}\right\} .
$$

To derive (38), we substitute for $\gamma^{0}=\zeta b /\left(k^{0}\left(1-\lambda_{3}^{0}\right)\right)$ in $(50)$.

The Golden Rule $k^{0}$ follows from $\left(1+i^{0}\right)=\alpha_{K} M\left(k^{0}\right)^{\left(\alpha_{K}-1\right)} S^{\alpha_{P}}=1$ and $(26)$ :

$$
k^{0}=\frac{\alpha_{K} \vartheta^{0}}{\sigma\left(1-\alpha_{K}\right)-\alpha_{K}},
$$

where $k^{0}>0 \Leftrightarrow \sigma\left(1-\alpha_{K}\right)>\alpha_{K}$. Furthermore, $\phi^{0}=(1-\zeta)\left[b-b^{\star} / \tilde{S}\right]$, and $\lambda_{3}^{0}=$ $\sigma^{2}\left(1-\alpha_{K}\right)^{2} / \alpha_{K}$. For $k^{0}>0$,

$$
\left(k^{0}\right)^{2}\left(1-\lambda_{3}^{0}\right)=\frac{\alpha_{K}\left(\vartheta^{0}\right)^{2}\left[\alpha_{K}-\sigma^{2}\left(1-\alpha_{K}\right)^{2}\right]}{\left[\sigma\left(1-\alpha_{K}\right)-\alpha_{K}\right]^{2}}>0
$$

and hence $\alpha_{K}>\sigma^{2}\left(1-\alpha_{K}\right)^{2}$. Thus, $\alpha_{K}$ is bounded from above and below: $\sigma^{2}\left(1-\alpha_{K}\right)^{2}<$ $\alpha_{K}<\sigma\left(1-\alpha_{K}\right)$.

Since $\phi^{0}=b-\vartheta^{0}<0$, it follows that $b<\vartheta^{0}$. According to (38), $\mathrm{d} V /\left.\mathrm{d} S\right|_{1+i=1}>0$ if and only if:

$$
\alpha_{K} b\left(b-\vartheta^{0}\right)+\frac{\alpha_{K}\left(\vartheta^{0}\right)^{2}\left[\alpha_{K}-\sigma^{2}\left(1-\alpha_{K}\right)^{2}\right]}{\left[\sigma\left(1-\alpha_{K}\right)-\alpha_{K}\right]^{2}}>0,
$$

where the first term is negative while the second can be signed positive. To evaluate the magnitude, we define an auxiliary function $\Phi(b) \equiv b\left(b-\vartheta^{0}\right)$. Since $\Phi(b)=0$ for $b=0 \vee b=\vartheta$ and since $\Phi(b)$ is convex in $b, \Phi(b)$ is minimal for $b \geq 0$ at $b_{\text {min }}=b^{\star} \tilde{S}^{-1} / 2$. Evaluating (51) for $b=b_{\text {min }}$, it is necessary (51) $>0, \forall b \geq 0$ that

$$
\frac{\alpha_{K}\left(b^{\star} \tilde{S}^{-1}\right)^{2}}{4\left[\sigma\left(1-\alpha_{K}\right)-\alpha_{K}\right]^{2}}\left\{(2-\zeta)^{2}\left[\alpha_{K}-\sigma^{2}\left(1-\alpha_{K}\right)^{2}\right]-(1-\zeta)\left[\sigma\left(1-\alpha_{K}\right)-\alpha_{K}\right]^{2}\right\}>0 .
$$


To show that this condition holds, we utilize that $(2-\zeta)^{2}>(1-\zeta)$ and furthermore, since $\sigma^{2}\left(1-\alpha_{K}\right)^{2}<\alpha_{K}<\sigma\left(1-\alpha_{K}\right)$,

$$
\left[\alpha_{K}-\sigma^{2}\left(1-\alpha_{K}\right)^{2}\right]>\left[\alpha_{K}-\sigma\left(1-\alpha_{K}\right)\right]>\left[\sigma\left(1-\alpha_{K}\right)-\alpha_{K}\right]^{2}
$$

Thus, $(51)>0, \forall b \geq 0$ and, consequently, $\mathrm{d} V /\left.\mathrm{d} S\right|_{1+i=1}>0$.

\section{A.5 Proof of Proposition 5}

(i) In analogy to part (i) of the Proof of Proposition 4, for $\phi<0$, i.e. $k^{\star}+b^{\star}-s^{\star}=\phi^{\star}>0$, we get $(1+i)\left(k^{\star}+b^{\star}\right)>k^{\star}+b^{\star}>s^{\star}=\sigma\left(w^{\star}-t^{\star}\right)$. Therefore, using (39), $\mathrm{d} V^{\star} / \mathrm{d} S>0$.

(ii) At the Golden Rule we know that $\left(1+\left(i^{\star}\right)^{0}\right)=1$, and hence $\left(\left(w^{\star}\right)^{0}-\left(\tau^{\star}\right)^{0}\right)=((1-$ $\left.\left.\alpha_{K}\right) / \alpha_{K}\right)\left(k^{\star}\right)^{0}$. Furthermore, $\left(k^{\star}\right)^{0}=h k^{0}$. To derive (40), we substitute for $\gamma^{0}=$ $\zeta b /\left(k^{0}\left(1-\lambda_{3}^{0}\right)\right)$ in (39). In analogy to part (ii) of the Proof of Proposition $4, \mathrm{~d} V^{\star} /\left.\mathrm{d} S\right|_{1+i=1}>$ 0 if $\phi>0$ and $\sigma^{2}\left(1-\alpha_{K}\right)^{2}<\alpha_{K}<\sigma\left(1-\alpha_{K}\right)$.

\section{A.6 Proof of Proposition 6}

From (13), $\phi^{\star}=-\phi h$ and furthermore $h>0$. To derive (41), we subtract (39) from (37) and utilize that $[(1+i)(k+b)-\sigma(w-\tau)]=(1+i) \phi+\sigma i(w-\tau),(w-\tau)=\left(1-\alpha_{K}\right) / \alpha_{K}(1+i) k-b i$, and analogously for Foreign. In accordance with Propositions 4- 5 we distinguish two cases.

Case i $\left(\phi>0 \Longleftrightarrow \phi^{\star}<0\right)$ : Since $\phi>0, \Delta>0$ and hence $\mathrm{d} V^{\star} / \mathrm{d} S<\mathrm{d} V / \mathrm{d} S$.

Case ii $\left(\phi<0 \Longleftrightarrow \phi^{\star}>0\right)$ : Since $\phi<0$ and knowing that in the Golden Rule $i=0, \Delta<0$ and hence $\mathrm{d} V^{\star} /\left.\mathrm{d} S\right|_{1+i^{\star}=1}>\mathrm{d} V /\left.\mathrm{d} S\right|_{1+i=1}$. 


\section{CESifo Working Paper Series}

for full list see www.cesifo-group.org/wp

(address: Poschingerstr. 5, 81679 Munich, Germany, office@cesifo.de)

2313 Ronel Elul and Piero Gottardi, Bankruptcy: Is it enough to Forgive or must we also Forget?, May 2008

2314 Andreas Irmen and Johanna Kuehnel, Productive Government Expenditure and Economic Growth, May 2008

2315 Beate Henschel, Carsten Pohl and Marcel Thum, Demographic Change and Regional Labour Markets: The Case of Eastern Germany, May 2008

2316 Gabriel Felbermayr, Wido Geis and Wilhelm Kohler, Restrictive Immigration Policy in Germany: Pains and Gains Foregone?, May 2008

2317 Michael Hofmann, Gerhard Kempkes and Helmut Seitz, Demographic Change and Public Sector Budgets in a Federal System, May 2008

2318 Paul De Grauwe, Macroeconomic Modeling when Agents are Imperfectly Informed, June 2008

2319 Johann K. Brunner and Susanne Pech, Optimum Taxation of Inheritances, June 2008

2320 Thomas Eichner and Marco Runkel, Corporate Income Taxation of Multinationals in a General Equilibrium Model, June 2008

2321 Rainald Borck and Matthias Wrede, Subsidies for Intracity and Intercity Commuting, June 2008

2322 Patricia Apps and Ray Rees, Testing the Pareto Efficiency of Household Resource Allocations, June 2008

2323 Amihai Glazer, Vesa Kanniainen and Panu Poutvaara, Firms' Ethics, Consumer Boycotts, and Signalling, June 2008

2324 Claudia M. Buch, Jörg Döpke and Kerstin Stahn, Great Moderation at the Firm Level? Unconditional vs. Conditional Output Volatility, June 2008

2325 Helmuth Cremer, Philippe De Donder, Dario Maldonado and Pierre Pestieau, Forced Saving, Redistribution and Nonlinear Social Security Schemes, June 2008

2326 M. Hashem Pesaran and Paolo Zaffaroni, Optimal Asset Allocation with Factor Models for Large Portfolios, June 2008

2327 Harald Badinger and Peter Egger, Horizontal versus Vertical Interdependence in Multinational Activity, June 2008 
2328 Jan K. Brueckner and Harris Selod, A Theory of Urban Squatting and Land-Tenure Formalization in Developing Countries, June 2008

2329 Paolo M. Panteghini, Corporate Debt, Hybrid Securities and the Effective Tax Rate, June 2008

2330 Guglielmo Maria Caporale, Juncal Cuñado and Luis A. Gil-Alana, Modelling Long-Run Trends and Cycles in Financial Time Series Data, June 2008

2331 Avi Ben-Bassat and Momi Dahan, Social Identity and Voter Turnout, June 2008

2332 Martin R. West and Ludger Wößmann, "Every Catholic Child in a Catholic School”: Historical Resistance to State Schooling, Contemporary Private Competition, and Student Achievement across Countries, June 2008

2333 Erkki Koskela and Panu Poutvaara, Outsourcing and Labor Taxation in Dual Labor Markets, June 2008

2334 Philippe Choné and Laurent Linnemer, Optimal Litigation Strategies with Signaling and Screening, June 2008

2335 Albert Solé-Ollé and Pilar Sorribas-Navarro, Does Partisan Alignment Affect the Electoral Reward of Intergovernmental Transfers?, June 2008

2336 Antonio Cabrales and Piero Gottardi, Markets for Information: Of Inefficient Firewalls and Efficient Monopolies, June 2008

2337 Sumon Majumdar and Sharun W. Mukand, The Leader as Catalyst - on Leadership and the Mechanics of Institutional Change, June 2008

2338 Ulrich Hange, Tax Competition, Elastic Labor Supply, and Growth, June 2008

2339 Guy Laroque and Bernard Salanié, Does Fertility Respond to Financial Incentives?, June 2008

2340 Adriano Paggiaro, Enrico Rettore and Ugo Trivellato, The Effect of Extending the Duration of Eligibility in an Italian Labour Market Programme for Dismissed Workers, June 2008

2341 Helmut Seitz, Minimum Standards, Fixed Costs and Taxing Autonomy of Subnational Governments, June 2008

2342 Robert S. Chirinko, Leo de Haan and Elmer Sterken, Asset Price Shocks, Real Expenditures, and Financial Structure: A Multi-Country Analysis, July 2008

2343 Wolfgang Leininger, Evolutionarily Stable Preferences in Contests, July 2008

2344 Hartmut Egger and Udo Kreickemeier, Fairness, Trade, and Inequality, July 2008 
2345 Ngo Van Long and Bodhisattva Sengupta, Yardstick Competition, Corruption, and Electoral Incentives, July 2008

2346 Florian Baumann, Employment Protection: The Case of Limited Enforceability, July 2008

2347 Alessandro Balestrino, Cinzia Ciardi and Claudio Mammini, On the Causes and Consequences of Divorce, July 2008

2348 Dirk Schindler and Benjamin Weigert, Insuring Educational Risk: Opportunities versus Income, July 2008

2349 Lammertjan Dam and Ben J. Heijdra, The Environmental and Macroeconomic Effects of Socially Responsible Investment, July 2008

2350 Avner Greif, Contract Enforcement and Institutions among the Maghribi Traders: Refuting Edwards and Ogilvie, July 2008

2351 Helmuth Cremer, Philippe De Donder, Dario Maldonado and Pierre Pestieau, Habit Formation and Labor Supply, July 2008

2352 Francesco Menoncin and Paolo M. Panteghini, The Johansson-Samuelson Theorem in General Equilibrium: A Rebuttal, July 2008

2353 Michael Kaganovich and Itzhak Zilcha, Alternative Social Security Systems and Growth, July 2008

2354 Keith Blackburn, Kyriakos C. Neanidis and M. Emranul Haque, Corruption, Seigniorage and Growth: Theory and Evidence, July 2008

2355 Edward Castronova, A Test of the Law of Demand in a Virtual World: Exploring the Petri Dish Approach to Social Science, July 2008

2356 Harald Badinger and Peter Egger, GM Estimation of Higher-Order Spatial Autoregressive Processes in Cross-Section Models with Heteroskedastic Disturbances, July 2008

2357 Wolfgang Buchholz and Jan Schumacher, Discounting the Long-Distant Future: A Simple Explanation for the Weitzman-Gollier-Puzzle, July 2008

2358 Luca Anderlini, Leonardo Felli and Alessandro Riboni, Statute Law or Case Law?, July 2008

2359 Guglielmo Maria Caporale, Davide Ciferri and Alessandro Girardi, Are the Baltic Countries Ready to Adopt the Euro? A Generalised Purchasing Power Parity Approach, July 2008

2360 Erkki Koskela and Ronnie Schöb, Outsourcing of Unionized Firms and the Impacts of Labour Market Policy Reforms, July 2008 
2361 Francisco Alvarez-Cuadrado and Ngo Van Long, A Permanent Income Version of the Relative Income Hypothesis, July 2008

2362 Gabrielle Demange, Robert Fenge and Silke Uebelmesser, Financing Higher Education and Labor Mobility, July 2008

2363 Alessandra Casarico and Alessandro Sommacal, Labor Income Taxation, Human Capital and Growth: The Role of Child Care, August 2008

2364 Antonis Adam, Manthos D. Delis and Pantelis Kammas, Fiscal Decentralization and Public Sector Efficiency: Evidence from OECD Countries, August 2008

2365 Stefan Voigt, The (Economic) Effects of Lay Participation in Courts - A Cross-Country Analysis, August 2008

2366 Tobias König and Andreas Wagener, (Post-)Materialist Attitudes and the Mix of Capital and Labour Taxation, August 2008

2367 Ximing Wu, Andreas Savvides and Thanasis Stengos, The Global Joint Distribution of Income and Health, August 2008

2368 Alejandro Donado and Klaus Wälde, Trade Unions Go Global!, August 2008

2369 Hans Gersbach and Hans Haller, Exit and Power in General Equilibrium, August 2008

2370 Jan P.A.M. Jacobs and Jan-Egbert Sturm, The Information Content of KOF Indicators on Swiss Current Account Data Revisions, August 2008

2371 Oliver Hülsewig, Johannes Mayr and Timo Wollmershäuser, Forecasting Euro Area Real GDP: Optimal Pooling of Information, August 2008

2372 Tigran Poghosyan and Jakob de Haan, Determinants of Cross-Border Bank Acquisitions in Transition Economies: A Latent Class Analysis, August 2008

2373 David Anthoff and Richard S.J. Tol, On International Equity Weights and National Decision Making on Climate Change, August 2008

2374 Florian Englmaier and Arno Schmöller, Reserve Price Formation in Online Auctions, August 2008

2375 Karl Farmer, Birgit Friedl and Andreas Rainer, Effects of Unilateral Climate Policy on Terms of Trade, Capital Accumulation, and Welfare in a World Economy, August 2008 